\title{
Low velocity axial impact crushing performance of empty recyclable metal beverage cans
}

\author{
Sivakumar Palanivelu ${ }^{1 *}$, Wim Van Paepegem ${ }^{1}$, Joris Degrieck ${ }^{1}$, Stijn De Pauw ${ }^{1}$, John Vantomme ${ }^{2}$, Jan \\ Wastiels $^{3}$, Dimitrios Kakogiannis ${ }^{3}$, Danny Van Hemelrijck ${ }^{3}$ \\ ${ }^{1}$ Department of Materials Science and Engineering, Ghent University, Sint-Pietersnieuwstraat 41, 9000 Gent, \\ Belgium \\ ${ }^{2}$ Royal Military Academy, Civil and Materials Engineering Department, Building G, Level 0, 8 Av. Hobbema \\ B-1000, Brussels, Belgium \\ ${ }^{3}$ Department of Mechanics of Materials and Constructions, Vrije Universiteit Brussel, Pleinlaan 2 B-1050 \\ Brussels, Belgium
}

\begin{abstract}
This paper focuses on the axial impact crushing behaviour of recyclable empty metal beverage cans available in the market. The idea is to make a macro-foam (sacrificial cladding structure) out of these cans to protect the main load bearing members of civil engineering structures from the air blast load. Axial drop weight tests have been conducted to understand the crushing characteristics and the corresponding energy absorption of a single empty beverage can in detail. To conduct such tests a small-scale drop weight test set-up has been designed and manufactured. The deformation mechanisms and the corresponding energy absorption of the beverage cans were studied in detail for different initial impact velocities $(1.4 \mathrm{~m} / \mathrm{s}, 2.2 \mathrm{~m} / \mathrm{s}, 3.1 \mathrm{~m} / \mathrm{s} .3 .8 \mathrm{~m} / \mathrm{s}, 4.4$ $\mathrm{m} / \mathrm{s}$ and $4.9 \mathrm{~m} / \mathrm{s}$ ). Furthermore, an analytical model is proposed to calculate the crushing parameters of empty metal beverage cans. The results from the analytical model are compared and validated with the experimental results.
\end{abstract}

KEYWORDS: Empty metal beverage can; Axial impact; Asymmetry deformation; Energy absorption; mean crush load; Analytical solution.

\section{Introduction}

Protecting the civilian population against blast attacks is a complex and comprehensive task. If critical civil structures (tower buildings, embassies etc.,) are threatened, the main concerns are with the elaboration of an efficient rescue plan and a rapid intervention. The structural integrity of the engineering structure itself is rarely considered. However, since the early nineties (bomb attacks World Trade Centre (1993), Oklahoma (1995), US embassy Kenya (1998),World Trade Centre (2001)) the protection of civil engineering structures against explosions has become an important research area. Efforts have been made around the globe to propose suitable solutions for this problem. Out of many proposed solutions, the concept of sacrificial cladding design [1-3] has attracted more attention in terms of its functionality and its predictable behaviour. Any sacrificial cladding structure can have two layers (an outer skin and an inner core). The function of the outer skin is to distribute the blast pressure more evenly to the inner core which deforms progressively so that the peak force transferred to the non-sacrificial structure can be minimized. In order to safeguard the main load bearing members of the civil engineering structures, the failure load of the sacrificial cladding structure should be kept as low as possible. Keeping a lower failure load for the inner core may attribute to achieve the plastic deformation during an explosion event and so the transferred peak force to the non-sacrificial structure can be minimised. Therefore, in this work, we propose empty recyclable metal beverage cans for the inner core members of the sacrificial cladding structure. The concept of the proposed sacrificial cladding structure using empty recyclable metal beverage cans is shown in Figure 1. This configuration can be used to protect typical civil engineering structures from air blast loading. The advantages of this sacrificial structure using empty beverage cans are: (i) environment friendly due to recyclable material (ii) it is a waste product and readily available in the market and (iii) non- 
corrosive due to inner lacquer and outer aesthetic coatings (iv) these cans can be adopted in different configurations of macro foam depending upon the blast loading magnitudes. As an example, two different configurations (axial and radial) of the macro foam assembly of empty beverage cans are shown in Figure 2.

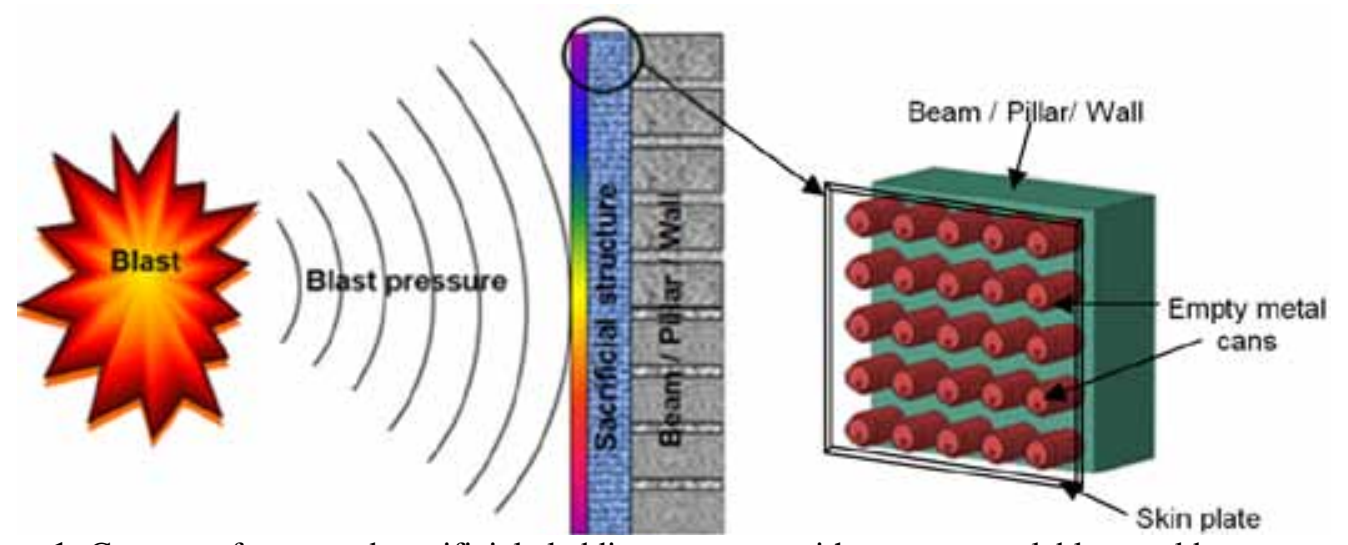

Figure 1: Concept of proposed sacrificial cladding structure with empty recyclable metal beverage cans.

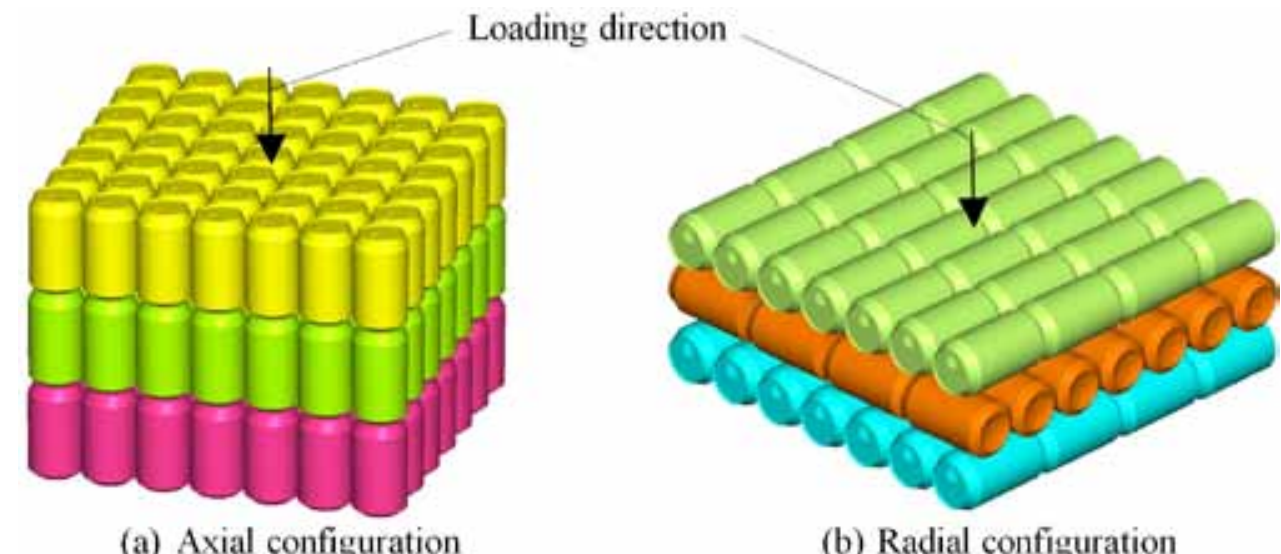

(a) Axial configuration

(b) Radial configuration

Figure 2: Two configurations of macro foam arrangement of empty recyclable metal beverage cans.

Before designing the inner core of a full-scale sacrificial cladding structure the knowledge of the crushing performance (progressive crushing stages and the corresponding energy absorption) of an individual beverage can is very important. Investigation of these factors during a blast loading is extremely difficult. Capturing the deformation mechanism, deformation pattern and the corresponding energy absorption during an impact test is relatively easier due to a slow speed of crushing. Therefore, to understand the above factors a detailed axial impact tests were conducted. However, the effect of strain rate on the deformation mechanisms and the corresponding deformation patterns of the beverage cans have to be further studied and verified for blast loading conditions.

Generic energy absorption devices which belong to two different categories (type I and II) based on their load-displacement curves were well studied in [4-10]. The loaddisplacement curve of type I is relatively "flat topped" and for type II the curve falls sharply after the peak crush load. The effect of "strain-rate factor" and the "inertia factor" on the above structures are also explained in those works. The general conclusions of the referred studies are as follows: (i) the deformation of type II structures is significantly more sensitive to the impact velocity than type I; (ii) when the total kinetic energy remains the same for all test specimens, smaller final deformations result from higher impact velocities and this 
phenomenon is much more significant for type II structures than type I; (iii) strain rate sensitivity and the inertia effect must be considered throughout the crushing process during an impact event. Tam and Calladine [11] studied the effect of strain rate and inertia on simple plate structures under impact loading. They explained two phases of deformation of type II structures which involves plastic compression and rotation at the plastic hinges.

Many studies have been conducted to study the crushing mechanism of the circular and square cross sectional thin-walled structures. The influence of impact velocity and the material characteristics on the dynamic buckling response of circular tubes during axial loading (quasi-static and impact) were studied in [12, 13]. In this work, the buckling mode to global bending was explained in terms of the material yield stress, strain hardening and the strain-rate sensitivity. This paper also proved that the energy absorption performance of cylindrical ductile tubes with high yield stress and low strain hardening is better than the one with low yield stress and high strain hardening. Similarly, the transition from initial global bending to progressive buckling on square and circular geometries was studied in [14]. Investigations of dynamic progressive crushing of cylindrical tubes indicate that the deformation is mainly started and concentrated at the end of the cylinder subjected to impulsive loading [15]. Furthermore, it deforms either axisymmetrically (concertina or ring mode) or asymmetrically (diamond mode), depending on the $D / t$ ratio (diameter - thickness) [16]. Experiments have shown that tubes with $D / t<80$ and rigid-perfectly plastic (low strainhardening) deform in concertina mode and the tubes with higher $D / t(>80)$ and sensitive to strain-hardening will deform into diamond mode [16-19]. Andrews et al. [20] further gave a guideline to predict the mode of deformation based on tube length to wall thickness ratio $(L / t)$ and diameter to wall thickness ratio $(D / t)$. Few studies also focussed on the switch of deformation pattern from concertina mode to diamond mode and mixed collapse of diamond and concertina modes [18, 20-22]. Hsu and Jones [22] observed tearing of the circular tube wall during the switch of deformation pattern from concertina to diamond mode. Pugsley [18] concluded that the transition from concertina to diamond mode occurs for $D / t=91$. The influence of other parameters on the switching of deformation patterns such as heat treatment and end constraints was also studied in ref. [23] and [21] respectively.

The mean crush load is the most important parameter in evaluating the energy absorption capacity of any structure. Hence, many theoretical models have been developed to study the mean crush load of the circular and square cross sectional tubular structures exhibiting axisymmetric and asymmetric deformation modes [16, 22, 24-26]. Alexander [25] was the first to provide an analytical model for the circular cross sectional tubes for axisymmetric failure mode. This model assumed the formation of three circumferential plastic hinges during the formation of a single fold; and when the fold goes outwards the material experiences circumferential tensile strain. Furthermore, the external work done is dissipated by plastic bending and circumferential stretching. In order to predict the occurrence and the position of the second peak within each fold Wierzbicki et al. [27] introduced a parameter known as the eccentricity factor (the ratio of outward fold to the whole fold length). This work has been further refined by Singace et al. [28] and Singace and Elsokby [29]. Similarly, few researchers have worked on diamond deformation mode [16, 30, 31]. Pugsley and Macaulay [18, 32] were the first researchers who initiated the work on diamond crushing mode. Later Johnson et al. [19] tried to develop a theoretical model for the diamond mode crushing based on the experiments with PVC tubes. Later Singace [16] proposed an improved solution to calculate the mean crush load of tubular structures. Most of the above analyses have focused on the quasi-static crushing of tubular structures. However, during a dynamic loading condition the strain-rate effect plays a key role to enhance the yield stress of the 
material. Abramowicz and Jones [24] suggested a method to extend the quasi-static mean crush load expression to dynamic loading condition considering the strain-rate effects.

In this work, to understand the crushing mechanisms, deformation patterns and the corresponding energy absorption of empty beverage cans axial impact tests have been conducted. The effect of initial impact velocities (strain rate effect) and the corresponding strain hardening on the crushing performance of the beverage can are studied. Furthermore, an analytical solution is proposed to calculate the dynamic mean crush load of the beverage can. The results from this analytical solution are also compared and validated with the experimental data.

\section{Test specimen and experimental set-up}

\subsection{Empty recyclable metal beverage cans}

Used empty recyclable metal beverage cans were selected for this experimental study. Special care was taken to choose cans without defects such as indents and scratches. The metal beverage cans available in the European market can be classified into two types based on the type of material they are made of. Type A is made of a combination of two materials; the entire body is made of steel and the top cover is made of aluminium (Figure 3(a)). Type B is completely made of aluminium. Due to the larger availability especially in Belgium, Type A was chosen for our experimental study. The measured average mass of a beverage can for this study was $26 \mathrm{~g}$. The details of the geometry of an empty metal beverage can are also shown in Figure 3(b). The corresponding material properties of the top cover and body of the beverage can are given in Table 1.

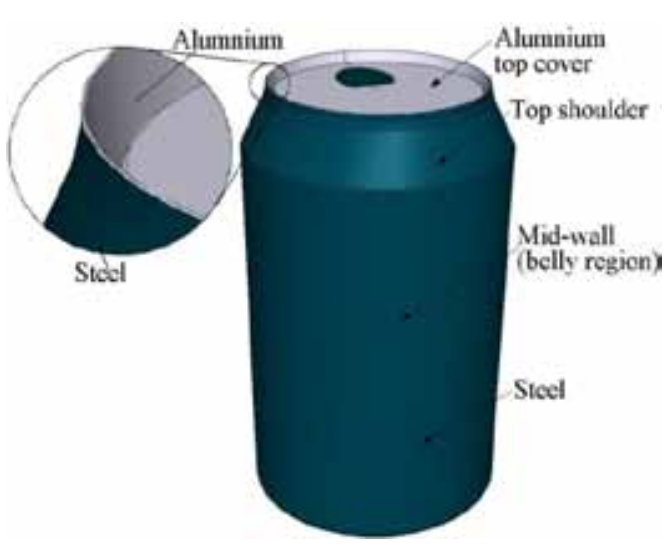

(a) Nomenclature and material details

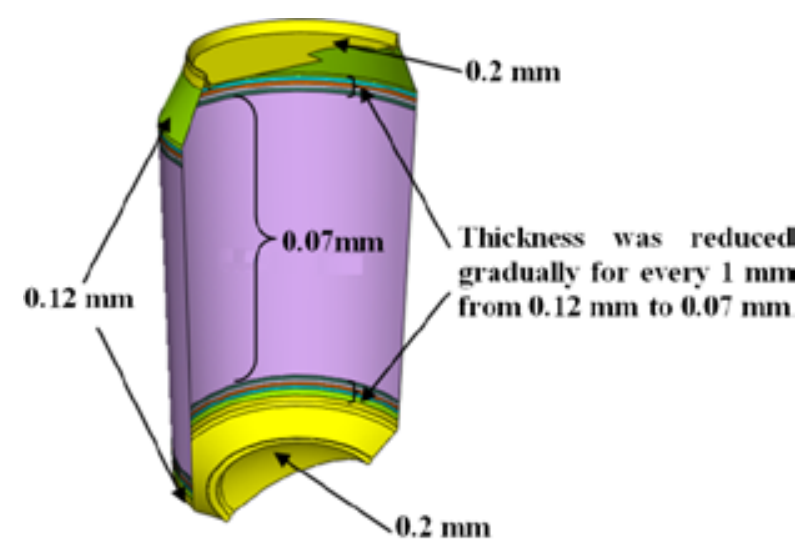

(b) Geometry details

Figure 3: Material and geometry details of an empty metal beverage can.

Table 1: Johnson-Cook and Cowper-Symonds parameters for top cover and body of the beverage can [33-37].

\begin{tabular}{|c|c|c|c|c|c|c|c|c|c|c|}
\hline \multirow[b]{2}{*}{ Material } & \multirow[b]{2}{*}{$\begin{array}{l}\text { Density } \\
\left(\mathrm{Kg} / \mathrm{m}^{3}\right)\end{array}$} & \multicolumn{7}{|c|}{ Johnson-Cook material parameters } & \multicolumn{2}{|c|}{$\begin{array}{c}\text { Cowper-Symonds } \\
\text { parameters }\end{array}$} \\
\hline & & $\begin{array}{c}\boldsymbol{C p} \\
(\mathrm{J} / \mathrm{Kg} \mathrm{K})\end{array}$ & $\begin{array}{l}T_{\text {melt }} \\
(\mathrm{K})\end{array}$ & $\begin{array}{c}A \\
(\mathrm{MPa})\end{array}$ & $\begin{array}{c}\boldsymbol{B} \\
(\mathrm{MPa})\end{array}$ & $n$ & $\boldsymbol{C}$ & $m$ & $\underset{\left(\mathrm{s}^{-1}\right)}{C}$ & $\boldsymbol{p}$ \\
\hline $\begin{array}{l}\text { Aluminium } 2024 \\
\text { (for top cover) }\end{array}$ & 2770 & 875 & 775 & 265 & 426 & 0.34 & 0.015 & 1.0 & 6500 & 4 \\
\hline $\begin{array}{l}\text { Steel } 4043 \text { (for } \\
\text { body of the can) }\end{array}$ & 7830 & 477 & 1793 & 792 & 510 & 0.26 & 0.014 & 1.03 & 200000 & 3.3 \\
\hline
\end{tabular}




\subsection{Experimental set-up and measurements of data}

The schematic representation of the experimental test set-up is shown in Figure 4. The vertical guides along which an impactor slides were fixed to a wall by means of horizontal supports. The impactor assembly slides on the vertical guides by roller ball bearings. The maximum drop height of the impactor for this set-up is $2 \mathrm{~m}$. The mass of the impactor, support structure for the test specimens and the end crushing part of the impactor can be varied as per the test specimen's requirement. An impactor mass of $7.7 \mathrm{~kg}$ was chosen for all tests. The experimental test set-up is fully instrumented with a dynamic force sensor and an accelerometer at the crushing end of the impactor to measure the reaction force and the acceleration of the impactor respectively. Furthermore, an inductive displacement sensor is also used to measure the drop height, instantaneous displacement of the impactor and the residual deformation length of the test specimen. Axial impact tests have been conducted with different impact heights which correspond to different initial impact velocities ranging from $1.4 \mathrm{~m} / \mathrm{s}$ to $4.9 \mathrm{~m} / \mathrm{s}$. A high speed camera (Photron APX RS 250K capable of recording $250,000 \mathrm{fps}$ ) was also used to capture the images during the test. A frame rate of $5000 \mathrm{fps}$ was used for these tests. A sampling frequency of $2 \mathrm{MHz}$ was chosen for all sensors (load cell, accelerometer and the inductive displacement sensor). In order to compare the deformation mechanism with the corresponding load-deformation curve all sensors and the high speed camera were triggered at the same time for recording the data.

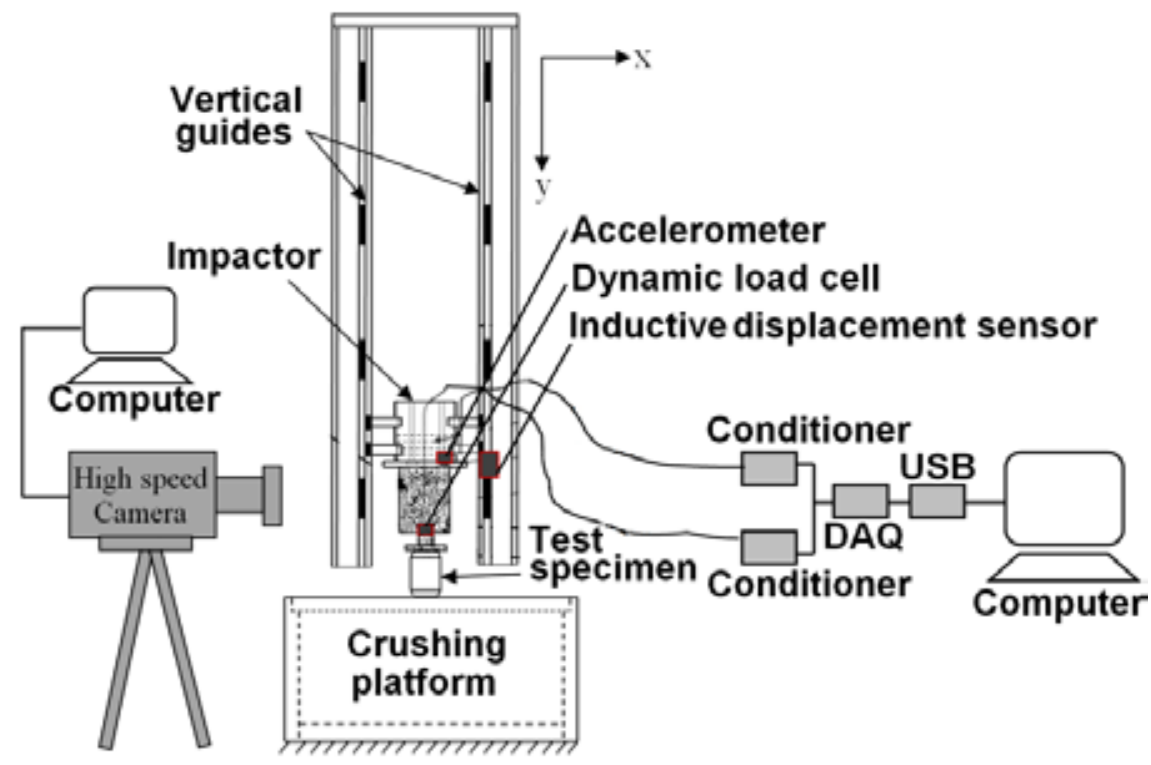

Figure 4: Schematic representation of the experimental set-up.

For all tests, the data from the different sensors have been checked and validated against each other. The integrated displacement from the accelerometer signal was validated with the signal from the inductive displacement sensor. As an example, one of the cases is presented here. Figure 5(a) shows the measured acceleration signal from the accelerometer for the initial impact velocity of $3.1 \mathrm{~m} / \mathrm{s}$ (only the relevant portion of the signal is shown here). To calculate the velocity and the corresponding displacement (equivalent to the deformation length of the test specimen) of the impactor the acceleration signal was integrated using trapezoidal integration rule without filtering the signal (the filtered signal also provided the same results). The corresponding integrated velocity and the displacement of the impactor are given in Figure 5(b) and 5(c) respectively. Furthermore, Figure 5(c) also shows the recorded signal from the inductive displacement sensor during the impact event. It can be noticed that the results from these two measurements provided almost the same result. 
Similarly, the load signal from the force sensor was validated with the load signal calculated from the accelerometer signal assuming that the impactor is a rigid body. It can be noticed from Figure 5(a) that the acceleration signal contains high frequency noise. Hence, the measured accelerometer signal was numerically filtered with a low-pass filter (with a cut-off frequency of $1500 \mathrm{~Hz}$ and a slope of $-100 \mathrm{~dB} /$ decade). To calculate the force signal the filtered accelerometer signal was multiplied by the mass of the impactor $(7.7 \mathrm{~kg})$. A comparison of these two signals is given in Figure 6. Similar to the displacement signals there was a good correlation observed for the force signals.
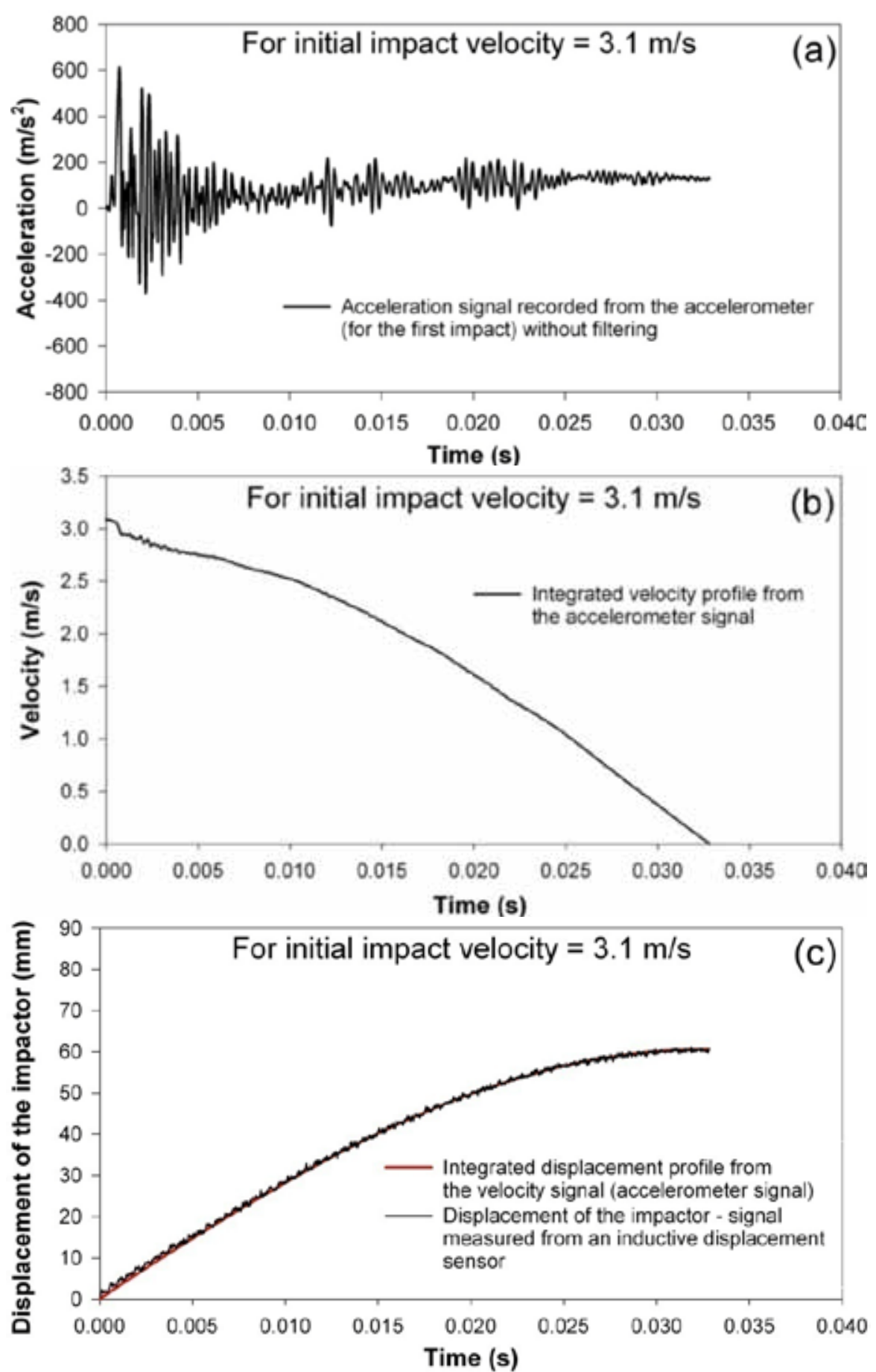

Figure 5: (a) measured accelerometer signal (without filtering). (b) Integrated velocity profile from the accelerometer signal (c) Comparison of the displacement (equivalent to the deformation length of the test specimen) profile from the integrated accelerometer signal and from an inductive displacement sensor. 


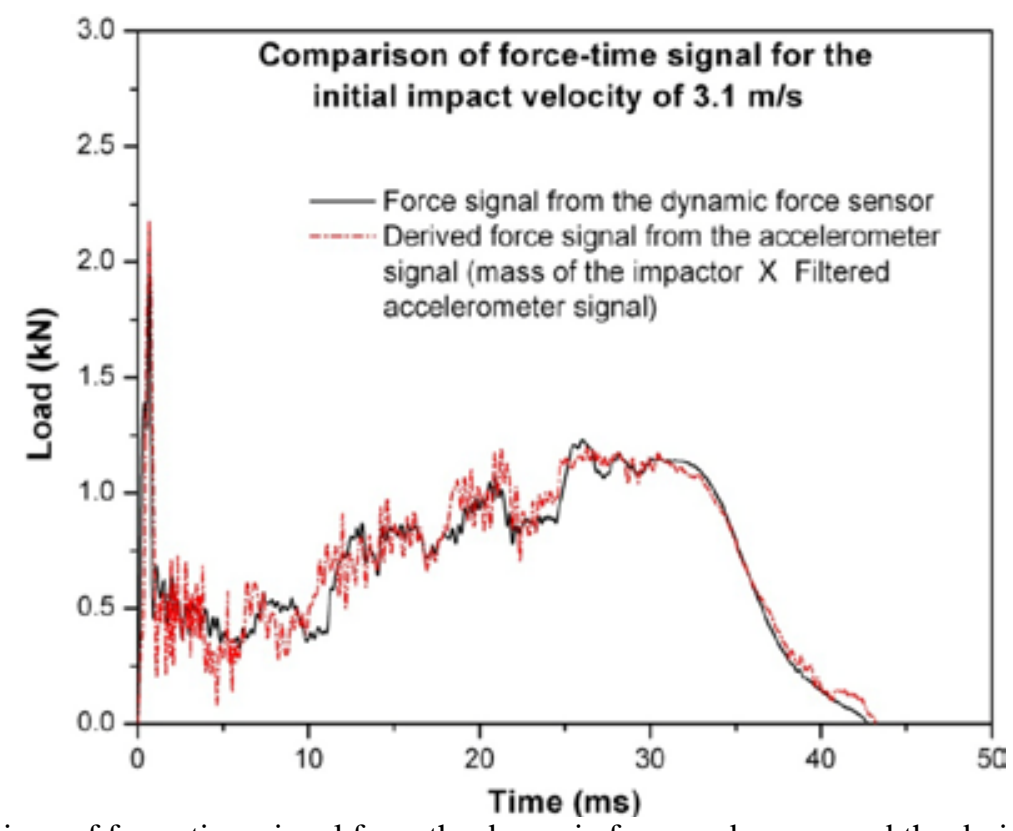

Figure 6: Comparison of force-time signal from the dynamic force and sensor and the derived signal from the accelerometer for the case with the initial impact velocity of $3.1 \mathrm{~m} / \mathrm{s}$.

\section{Experimental results and discussions}

The crushing performance of empty beverage cans was studied for different initial impact velocities such as $1.4 \mathrm{~m} / \mathrm{s}, 2.2 \mathrm{~m} / \mathrm{s}, 3.1 \mathrm{~m} / \mathrm{s}, 3.8 \mathrm{~m} / \mathrm{s}, 4.4 \mathrm{~m} / \mathrm{s}$ and $4.9 \mathrm{~m} / \mathrm{s}$. For each case a minimum of ten tests have been carried out and the average of all the parameters were taken into account to calculate the performance parameters which are discussed in the next section. The empty beverage cans showed a controlled and progressive failure pattern for all cases. As an example, the different phases of empty beverage can crushing subjected to an initial impact velocity of $4.9 \mathrm{~m} / \mathrm{s}$ are shown in Figure 7.

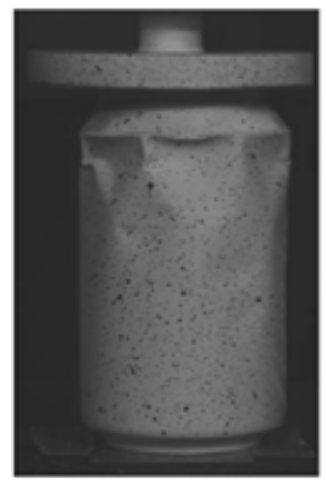

$\mathrm{t}=0.635 \mathrm{~ms}$

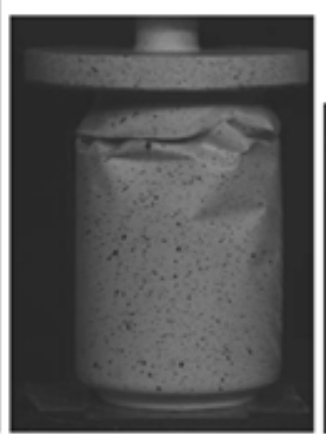

$\mathrm{t}=3.81 \mathrm{~ms}$

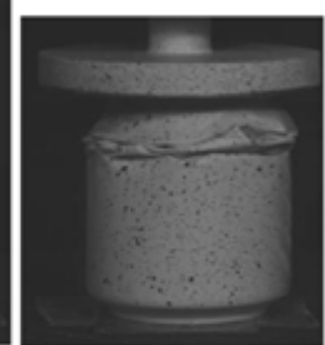

$\mathrm{t}=11.02 \mathrm{~ms}$

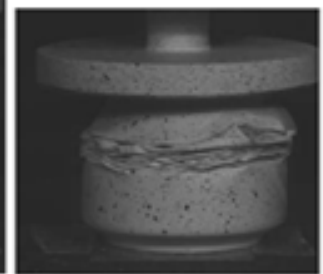

$\mathrm{t}=19.05 \mathrm{~ms}$

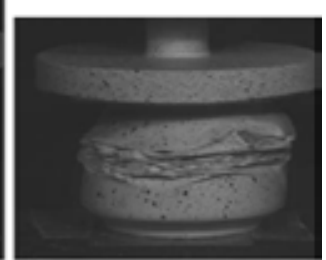

$\mathrm{t}=26.66 \mathrm{~ms}$

Figure 7: Progressive crushing stages of empty beverage can for an initial impact velocity of $4.9 \mathrm{~m} / \mathrm{s}$.

\subsection{Collapse modes}

The final deformation patterns of the empty beverage cans for different initial impact velocities are shown in Figure 8(a-f). These cans are painted after the test due to the intellectual property rights (except the one which is shown in Figure 7). Based on the thickness distribution of an empty beverage can, it can be concluded that the initial deformation should occur at the mid-wall location (belly portion) of the can due to its lower 
thickness $(0.07 \mathrm{~mm})$. However, for the case with an initial impact velocity of $1.4 \mathrm{~m} / \mathrm{s}$ the deformation occurred at different points of the can along its length (plastic local wall buckling and folding). The difference in the deformation pattern of the cans may be influenced by a combination of two effects: (i) the initial geometry imperfections induced during the manufacturing process and during usage and (ii) a lower impact velocity of the impactor. The average deformation length of the beverage can for this case was $17.5 \mathrm{~mm}$.
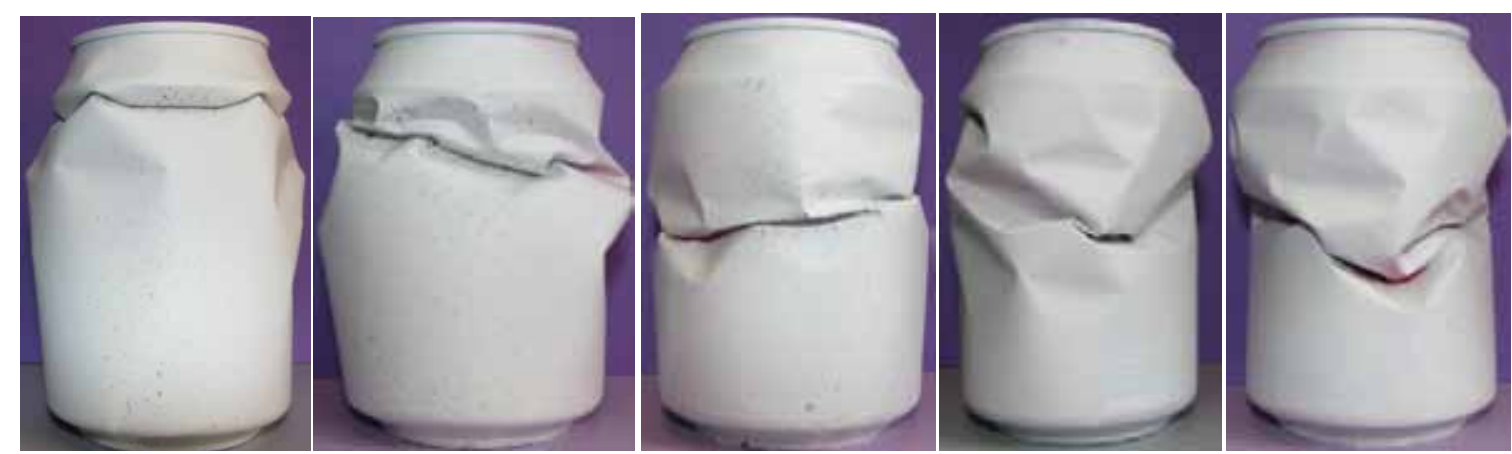

(a) Deformation patterns for initial impact velocity $1.4 \mathrm{~m} / \mathrm{s}$
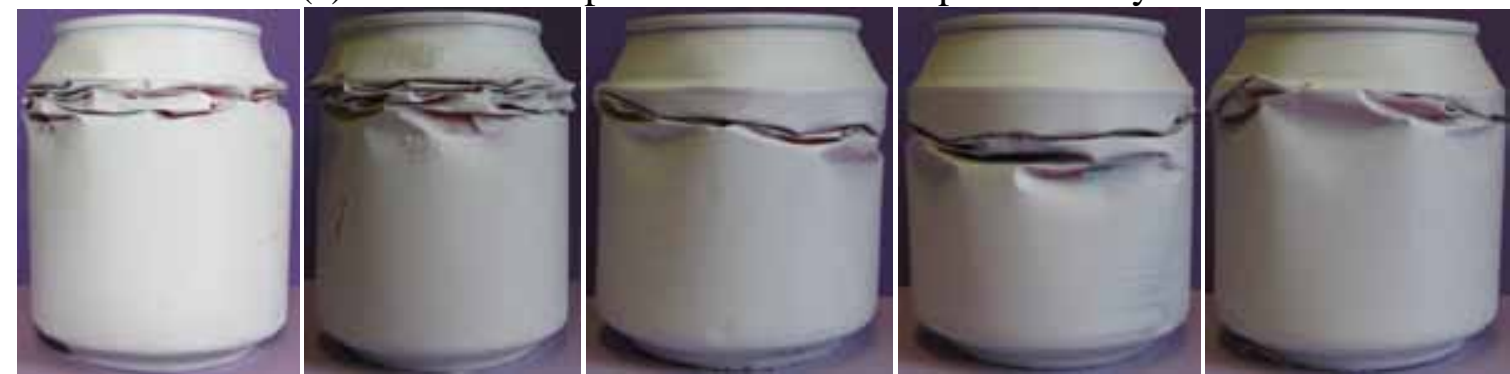

(b) Deformation patterns for initial impact velocity $2.2 \mathrm{~m} / \mathrm{s}$
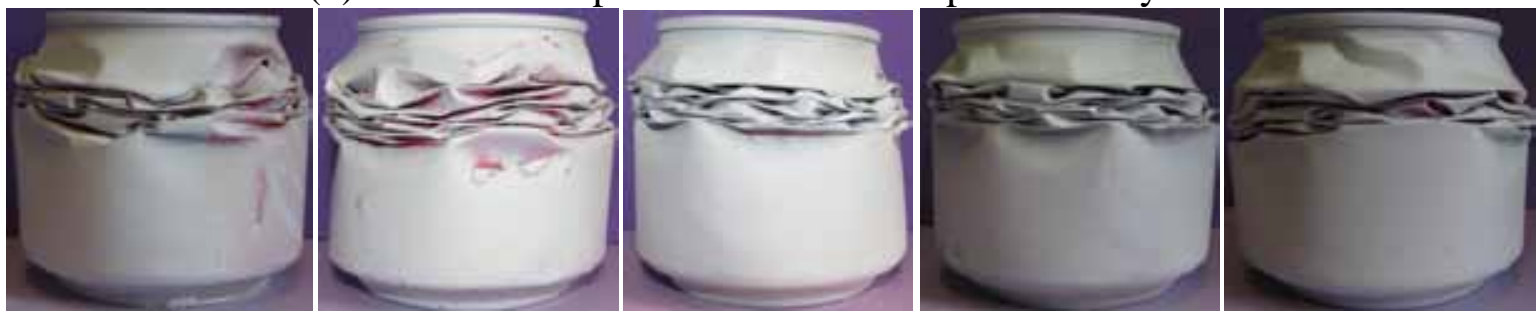

(c) Deformation patterns for initial impact velocity $3.1 \mathrm{~m} / \mathrm{s}$
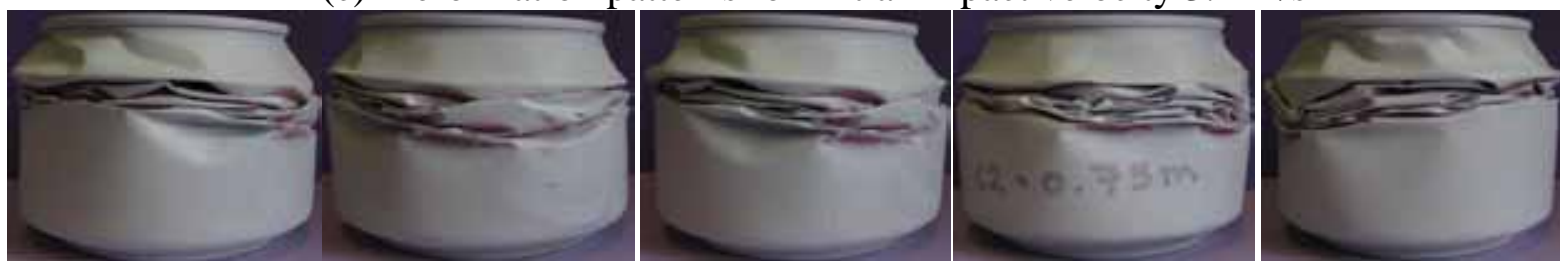

(d) Deformation patterns for initial impact velocity $3.8 \mathrm{~m} / \mathrm{s}$ 


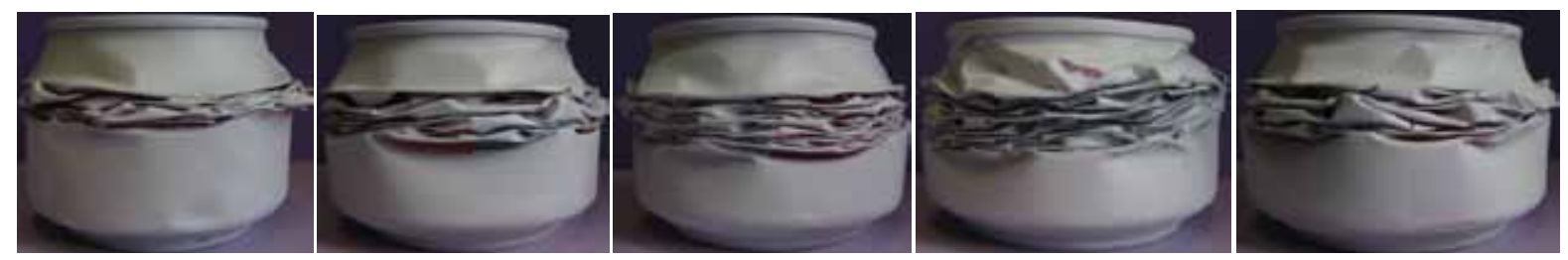

(e) Deformation patterns for initial impact velocity $4.4 \mathrm{~m} / \mathrm{s}$
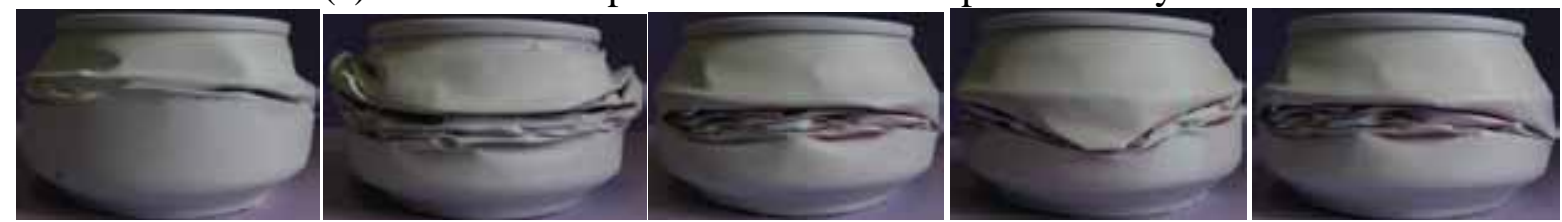

(f) Deformation patterns for initial impact velocity $4.9 \mathrm{~m} / \mathrm{s}$

Figure 8: Final deformation patterns of empty recyclable metal beverage cans for different impact velocities. (a) $1.4 \mathrm{~m} / \mathrm{s}$ (b) $2.2 \mathrm{~m} / \mathrm{s}$ (c) $3.1 \mathrm{~m} / \mathrm{s}$ (d) $3.8 \mathrm{~m} / \mathrm{s}$ (e) $4.4 \mathrm{~m} / \mathrm{s}$ (f) $4.9 \mathrm{~m} / \mathrm{s}$.

The deformation patterns of the beverage cans for all other impact velocities $(2.2 \mathrm{~m} / \mathrm{s}$, $3.1 \mathrm{~m} / \mathrm{s}, 3.8 \mathrm{~m} / \mathrm{s}, 4.4 \mathrm{~m} / \mathrm{s}$ and $4.9 \mathrm{~m} / \mathrm{s}$ ) are different from the earlier case (refer Figure 8(b f)). The chronological order of the initiation of the folding process and the corresponding collapse mode can be understood from the high speed images (refer Figure 9). For these cases, an initial elastic local wall buckling started below the top shoulder region which caused to form few fold legs around the circumference (indicated in Figure 9). The initial elastic local wall buckling (towards the inside of the can) was always axisymmetric. Furthermore, the location of local wall buckling and the corresponding fold legs below the top shoulder region was consistent for these cases $(2.2 \mathrm{~m} / \mathrm{s}, 3.1 \mathrm{~m} / \mathrm{s}, 3.8 \mathrm{~m} / \mathrm{s}, 4.4 \mathrm{~m} / \mathrm{s}$ and 4.9 $\mathrm{m} / \mathrm{s}$ ). This was due to the combined effect of higher impact velocity, inertia of the impactor and a lower geometrical thickness of the beverage can at that location. The formation of fold legs removed the cylindrical curvature of the beverage can and converted it into a ring of triangles. During further crushing the base of the triangular fold inclined towards the axis of the beverage can and the apex started to move away from the axis of the beverage can. When the fold legs reach a critical angle the elastic hinge became plastic which facilitated for axial bending and subsequent fold formation. Due to the presence of loading, the de-curving process continues for all triangle folds until the distance from the apex to the base of the triangle (called as half fold length $H$ ) becomes invariable. During the above process an initiation of another set of fold legs occurred below. At later crushing phases the deformation propagated downwards along its length and crushed progressively in a diamond mode which caused an asymmetric failure pattern (refer Figure 7, 9 and 10). The occurrence of the diamond mode deformation depends upon the combined effect of $D / t$ ratio $(\sim 937$ for beverage can) and material strain hardening characteristics [16]. During the crushing process, the diamond folding of the wall of the beverage can occur partially inside and partially outside from the mean diameter. Experiments have shown that the wall of a concertina mode deformed tube will be laid down partly to the inside and partly to the outside of the mean diameter; furthermore, it was proved that the outward part is usually bigger than the inward part [27]. However, in case of asymmetric deformation mode (diamond mode) the inward part of the fold is found to be bigger than the outward fold. Similar evidence can be noticed from Figure 10, where the inward fold or lobes are bigger than outwards. Therefore, the eccentricity factor for a diamond mode deformation can be defined as the ratio of the inward part to the total folding length $[21,28]$. 


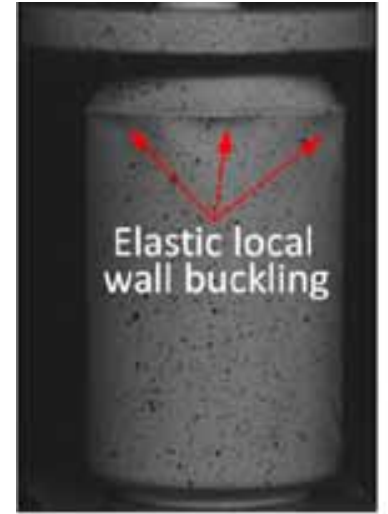

$\mathrm{t}=0.317 \mathrm{~ms}$

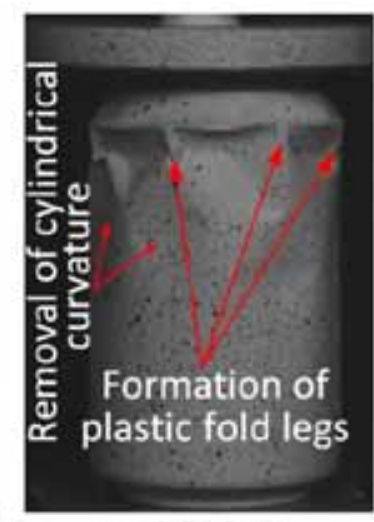

$\mathrm{t}=0.725 \mathrm{~ms}$

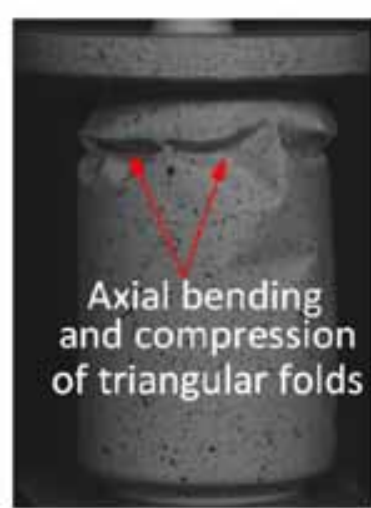

$\mathrm{t}=1.11 \mathrm{~ms}$

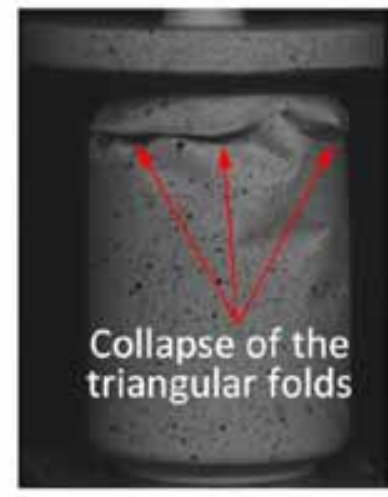

$\mathrm{t}=3.33 \mathrm{~ms}$

Figure 9: Chronological order of initiation and folding of fold legs and triangular folds during crushing of an empty beverage can.

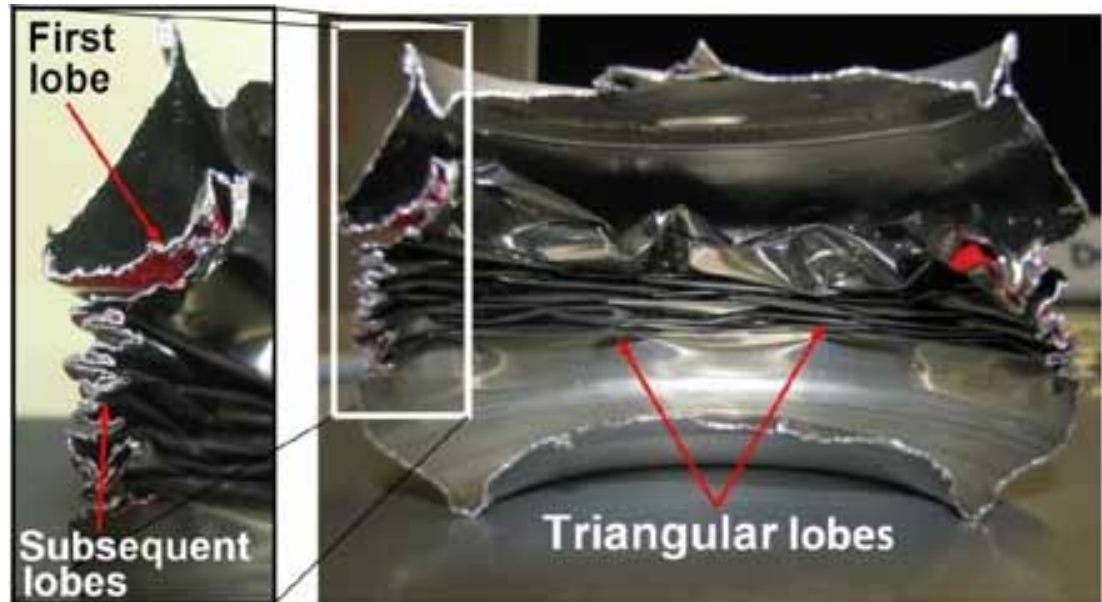

Figure 10: Cut sectional view of beverage cans for initial impact velocity of $3.8 \mathrm{~m} / \mathrm{s}$.

The number of circumferential triangular segments or lobes varied from a minimum of 5 to a maximum of 8 . The higher $D / t$ ratio of the beverage can facilitated to form a larger number of triangular lobes [16]. As an example, the geometric relationships for an empty beverage can that deformed into six circumferential lobes are given in Figure 11(a) and (b). For the case with an initial impact velocity of $2.2 \mathrm{~m} / \mathrm{s}$ the formation of triangular lobes occurred for 2 rows simultaneously. For all cases, the length of the first lobe was always longer than for the others. The longitudinal cut-section of these test specimens confirmed the same (refer Figure 10). This may be due to the combined effect of initial impact velocity and impactor inertia on the initial compression phase of the beverage can. The average half folding length of each lobe and the corresponding numbers were increased with increasing initial impact velocities (refer Figure 10). The average half folding length varied from a minimum of $2.1 \mathrm{~mm}$ to a maximum of $4.5 \mathrm{~mm}$. For higher initial impact velocities such as $3.8 \mathrm{~m} / \mathrm{s}, 4.4 \mathrm{~m} / \mathrm{s}$ and $4.9 \mathrm{~m} / \mathrm{s}$, the impactor rebounded after reaching the maximum deformation length of the test specimen; subsequently, successive impacts were observed for these cases. This was due to the densification of lobes and the corresponding strain hardening of the material. However, the successive impacts were not taken into account for the energy absorption calculation. Compared to the thickness of a bright can (can without any coating) the thickness of the aesthetic coating on the outer surface and lacquer coating (used to prevent the contact of beverage with metal) at the inner surface was negligible. Hence, it can be concluded that the effect of these coatings on the deformation mechanisms and the corresponding energy absorption was negligible. However, a detailed study on bright cans is 
needed for the final conclusion of this statement. For all cases, no significant deformation was noticed at top and bottom shoulder and end caps (refer Figure 8 (a-f)).

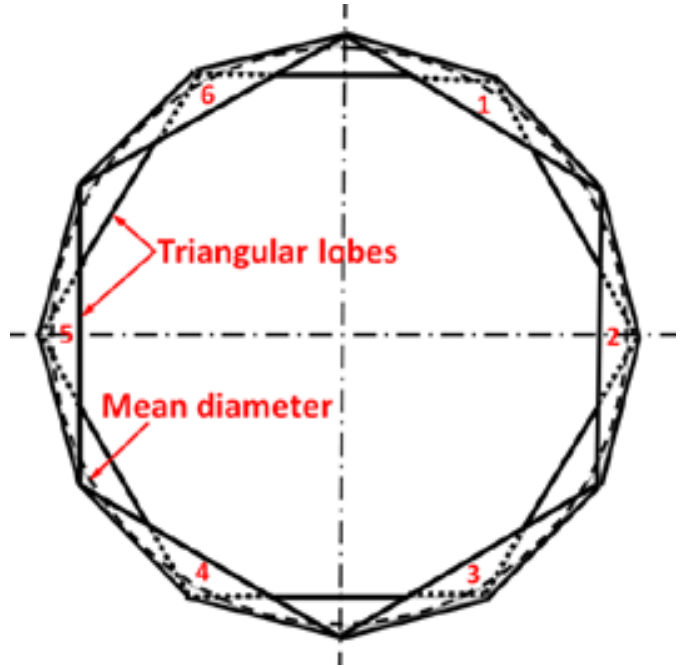

(a)

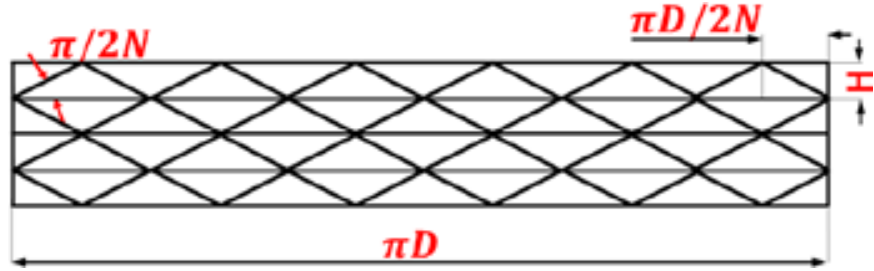

(b)

Figure 11: Deformed view of a beverage can with six lobes (a) Top view (b) Developed view.

\subsection{Typical load-deformation curves}

The measured crushing load of the beverage cans can be expressed in terms of the impactor acceleration as (Equation 1),

$$
F_{c}(t)=M_{I} \cdot[a(t)+g]
$$

where $F_{c}(t)$ is the instantaneous crushing load of an empty beverage can which was measured by a dynamic load cell at the crushing end; $M_{I}$ is the mass of the impactor $(7.7 \mathrm{~kg}) ; a(t)$ is the acceleration of the impactor $\left(\mathrm{m} / \mathrm{s}^{2}\right) ; g$ is the acceleration due to gravity $\left(\mathrm{m} / \mathrm{s}^{2}\right)$. The velocity of the impactor $(v(t))$ and the corresponding displacement $(l(t))$ which is equivalent to the deformation length of the test specimen can be written as (Equation 2 and 3),

$$
\begin{array}{cc}
v(t)=\int_{0}^{t} a(t) \cdot d t & v(0)=v_{0}(m / s) \\
l(t)=\int_{0}^{t} v(t) \cdot d t & l(0)=0(m)
\end{array}
$$

where $v_{0}$ is the initial impact velocity which is varied from a minimum of $1.4 \mathrm{~m} / \mathrm{s}$ to a maximum of $4.9 \mathrm{~m} / \mathrm{s}$. From equations 1 and 3 the total absorbed energy ( $E_{a b s}$ ) by an empty beverage can for each initial impact velocity can be calculated from the following relation (Equation 4),

$$
E_{a b s}=\int_{0}^{l_{\max }} F(l) \cdot d l[\mathrm{~J}]
$$

where $F(l)$ is the instantaneous crushing load corresponding to the instantaneous crushing deformation length of the beverage can $d l . l_{\max }$ is the maximum or total deformation length of 
the test specimen (for the first impact). Similarly, the total energy given by the impactor can be calculated from the following relation (Equation 5)

$$
E_{\text {given }}=\frac{1}{2} M_{I} \cdot v_{0}^{2}+\int_{0}^{l_{\max }} M_{I} \cdot g \cdot d l[\mathrm{~J}]
$$

In Equation 5, the first term on the right hand side of the equation corresponds to the initial kinetic energy given by the impactor before impact and the second term corresponds to an additional potential energy due to the travelling mass of the impactor during the crushing process. The calculated average values (from 10 experiments for each case) are given in Table 2. From Table 2, it can be noticed that there was a difference in the energy levels between the total energy given by the impactor $\left(E_{\text {given }}\right)$ and the energy absorbed by the beverage can $\left(E_{a b s}\right)$ (varied from approximately 2 to $3.5 \%$ for the initial impact velocity of $1.4 \mathrm{~m} / \mathrm{s}$ to $4.4 \mathrm{~m} / \mathrm{s}$ ). The reason for the difference can be attributed to: (i) the friction between the roller ball bearing of the impactor and the supporting guides (ii) air resistance to the impactor (iii) energy loss due to the impacting sound (iv) friction between the impactor and the test specimen during crushing (v) energy absorbed by the impactor by elastic deformation (vi) heat dissipation during the plastic deformation of the can. However, for the case with the initial impact velocity of $4.9 \mathrm{~m} / \mathrm{s}$ the difference $\left(E_{\text {given }}-E_{a b s}\right)$ was higher compared to other cases (approximately $7.7 \%$ ). An investigation and the corresponding reason for this difference are presented in section 3.2.1.

A preliminary quasi-static study of the empty beverage cans clearly indicated the strain-rate dependency on their material deformation and their peak crush load (refer Figure 12). The peak crush load of an empty beverage can varied from 1.1 to $1.4 \mathrm{kN}$ for 0.002 to $0.037 \mathrm{~s}^{-1}$ rate of loading. For the simplification the crushing compressive load and the deformation length are shown in positive values in all load-deformation graphs. From the quasi-static and impact experimental results it can be concluded that these structures performed as type-II structures which we discussed in the Introduction section.

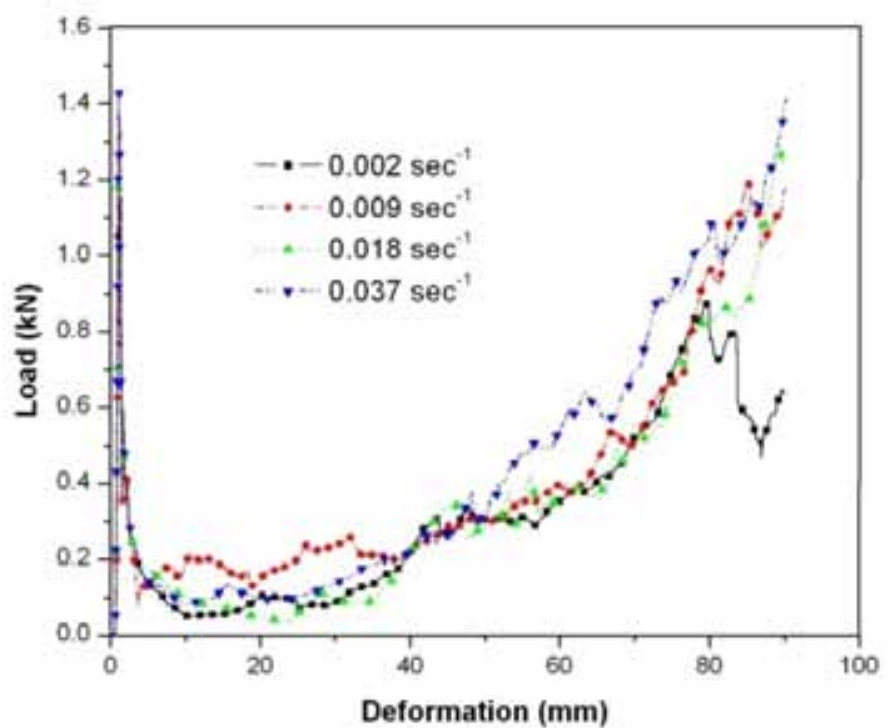

Figure 12: Quasi-static load-deformation curves of empty beverage cans at different strain rates

As an example, one of the load-deformation profiles of the empty beverage cans for each initial impact velocity are given in Figure 13(a - f). The initial peak crush load 
corresponds to the initial formation of fold legs which altered the cylindrical curvature of the can and subsequent plastic folding into a certain number of triangular lobes. Immediately after the peak load there was a reduction in the load noticed; this stage corresponded to the complete collapse or rotation of the triangular lobes about their base. At the end of this process, the subsequent formation of another set of fold legs occurred and these processes continued. This phenomenon can be noticed from Figure 13(b- f); after the peak crush load the load fluctuated in the form of a triangle. The increase in load corresponds to the formation of new fold legs and the drop in the load corresponds to the collapse or compression of triangular lobes. The number of triangles in the curve indicates the number of folds along its length. Furthermore, it can be noticed from these figures that the fold length increases with increasing initial impact velocities (refer Figure 13(c) and 13(e)). In all load - deformation curves (except $1.4 \mathrm{~m} / \mathrm{s}$ initial velocity) after achieving $20 \mathrm{~mm}$ of deformation length the crush load of the can increased considerably; this was due to the onset collapse and the corresponding compression of triangular lobes. Furthermore, the strain hardening characteristics of the material significantly contributed for this increasing crush load. From the load-deformation curves of successive tests, it can be noticed that the peak crushing load of an empty beverage can varied from $1.8 \mathrm{kN}$ to $2.4 \mathrm{kN}$ (a minimum of 10 tests for each case) and it is increasing with higher initial impact velocities (Figure 13). These values are significantly higher than from quasi-static results ( 1.1 to $1.4 \mathrm{kN}$ for 0.002 to $0.037 \mathrm{~s}^{-1}$ rate of loading). This shows a clear evidence of strain-rate dependency of the material. 

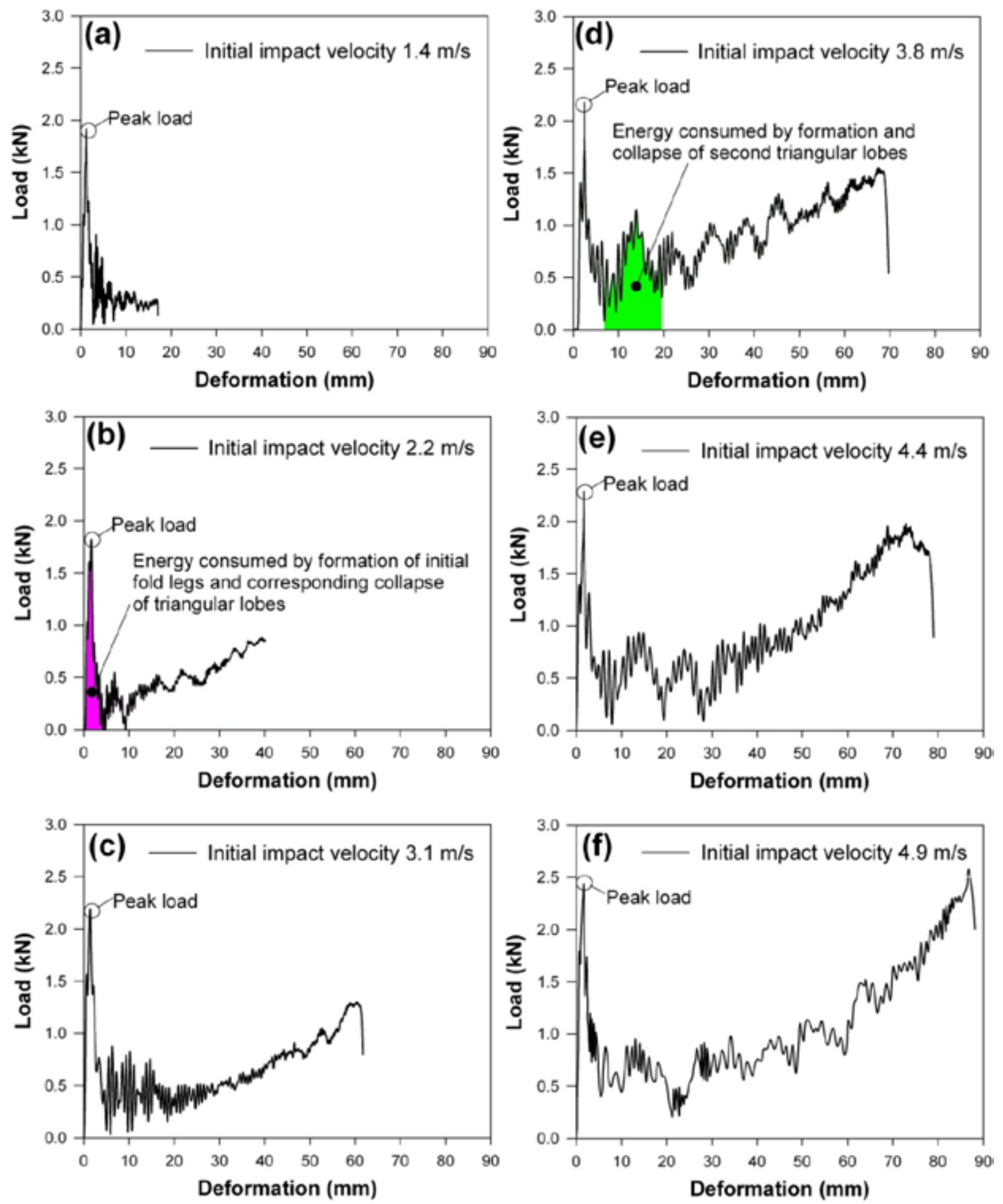

Figure 13: Force-deformation histories of empty beverage cans: (a) for initial impact velocity of $1.4 \mathrm{~m} / \mathrm{s}$. (b) for initial impact velocity of $2.2 \mathrm{~m} / \mathrm{s}$. (c) for initial impact velocity of $3.1 \mathrm{~m} / \mathrm{s}$. (d) for initial impact velocity of 3.8 $\mathrm{m} / \mathrm{s}$. (e) for initial impact velocity of $4.4 \mathrm{~m} / \mathrm{s}$. (f) for initial impact velocity of $4.9 \mathrm{~m} / \mathrm{s}$.

When characterizing the energy absorption capacity of a material or structure the following three important parameters have to be considered. The first parameter is the mean load ( $P_{\text {mean }}$ - can be calculated using Equation 6$)$; it is a measure of average force required to deform the material in a progressive manner. The second important parameter is the specific energy absorption (SEA - energy absorbed per unit mass of the crushed material) which provides a measure of the energy absorption ability of a structural component (Equation 7). 
The third parameter crush efficiency $\left(\eta_{c}\right)$ gives an idea about how ideal a structural component for energy absorption behaves (Equation 8). The ideal value is $100 \%$ which means that after the initiation of crushing (peak crush load) the load will remain the same (mean load). A low percentage is not desirable because a higher initial force (acceleration) will be transferred to the mounting structure.

$$
\begin{gathered}
P_{\text {mean }}=\frac{\int_{0}^{l_{\max }} F(l) \cdot d l}{l_{\max }}[\mathrm{kN}] \\
S E A=\frac{\int_{0}^{l_{\max }} F(l) \cdot d l}{m_{b c}}[\mathrm{~J} / \mathrm{g}] \\
\eta_{c}=\frac{P_{\text {mean }}}{P_{\max }}(\%)
\end{gathered}
$$

where $m_{b c}$ is the mass of an empty beverage can for maximum length of deformation (an equivalent mass over length was considered); $P_{\max }$ is the peak crush load of each empty beverage can. The calculated average values (from 10 test specimens) of each case are given in Table 2. The results from these tests provided clear guidelines for the deployment of beverage cans for the sacrificial cladding structure. For the case with initial impact velocity of $4.9 \mathrm{~m} / \mathrm{s}$ the crush load $(\sim 2.68 \mathrm{kN})$ was increased beyond the initial peak crush load $(\sim 2.46$ $\mathrm{kN}$ ) after reaching the deformation length of about $83 \mathrm{~mm}$. Hence, a higher acceleration could be transferred at the end of the crushing. Therefore, limiting the deformation length below $80 \mathrm{~mm}$ would provide tolerable acceleration to the mounting structure. However, the deformation mechanism and mode are to be further verified for explosive loading conditions. Furthermore, as we noticed the peak crush load increased with increasing the initial impact velocities which corresponds to a higher acceleration to the mounting structure. 
Table 2: Summary of average crushing parameters (from 10 tests of each category).

\begin{tabular}{|c|c|c|c|c|c|c|c|c|c|c|c|}
\hline 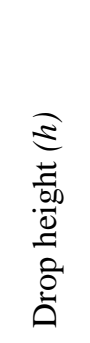 & 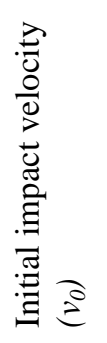 & 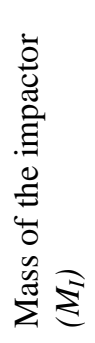 & 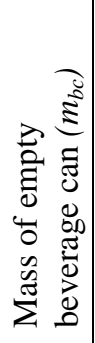 & 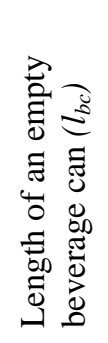 & 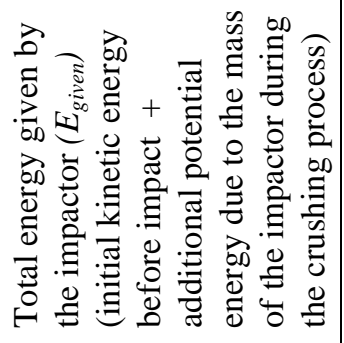 & 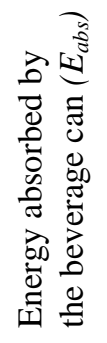 & 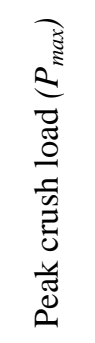 & 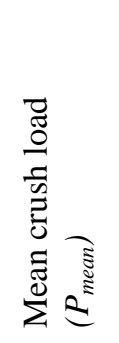 & 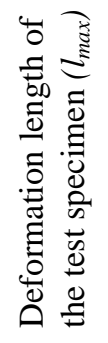 & 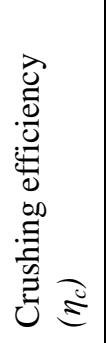 & 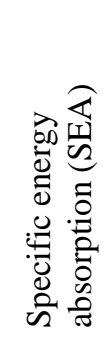 \\
\hline (m) & $(\mathrm{m} / \mathrm{s})$ & (kg) & (g) & $(\mathrm{mm})$ & $(\mathrm{J})$ & $(\mathrm{J})$ & $(\mathrm{kN})$ & $(\mathrm{kN})$ & $(\mathrm{mm})$ & (\%) & $(\mathrm{kJ} / \mathrm{kg})$ \\
\hline \multicolumn{12}{|c|}{ Experimental } \\
\hline 0.1 & 1.4 & \multirow{6}{*}{7.7} & \multirow{6}{*}{26} & \multirow{6}{*}{117} & 8.9 & 8.7 & 1.69 & 0.413 & 18.1 & 24.4 & 2.16 \\
\hline 0.25 & 2.2 & & & & 21.8 & 21.1 & 1.72 & 0.446 & 42.1 & 25.9 & 2.25 \\
\hline 0.5 & 3.1 & & & & 41.5 & 40.2 & 2.19 & 0.610 & 60.6 & 27.8 & 2.98 \\
\hline 0.75 & 3.8 & & & & 60.9 & 59.0 & 2.28 & 0.774 & 71.8 & 33.9 & 3.69 \\
\hline 1.0 & 4.4 & & & & 80.5 & 77.5 & 2.37 & 0.918 & 80.0 & 38.7 & 4.37 \\
\hline 1.25 & 4.9 & & & & 98.9 & 91.3 & 2.46 & 1.060 & 86.7 & 43.0 & 4.75 \\
\hline $1.25^{*}$ & $4.9^{*}$ & & & & $100.0^{*}$ & $95.4^{*}$ & $2.47^{*}$ & $0.998^{*}$ & $95.5^{*}$ & $38.8^{*}$ & $4.49^{*}$ \\
\hline \multicolumn{12}{|c|}{ *Tests have been conducted with beverage cans having 4 holes ( $\phi 3.5 \mathrm{~mm}$ each) at the bottom (refer Figure 15). } \\
\hline \multicolumn{12}{|c|}{ Analytical using Equation (20) } \\
\hline 0.25 & 2.2 & \multirow{5}{*}{7.7} & \multirow{5}{*}{26} & \multirow{5}{*}{117} & 21.9 & 21.9 & - & 0.495 & 44.2 & - & 2.22 \\
\hline 0.5 & 3.1 & & & & 41.6 & 41.6 & - & 0.673 & 61.8 & - & 3.02 \\
\hline 0.75 & 3.8 & & & & 61.2 & 61.2 & - & 0.808 & 74.5 & - & 3.70 \\
\hline 1.0 & 4.4 & & & & 80.7 & 80.7 & - & 0.968 & 83.3 & - & 4.35 \\
\hline 1.25 & 4.9 & & & & 99.0 & 99.0 & - & 1.120 & 88.4 & - & 5.03 \\
\hline
\end{tabular}

\subsubsection{Effect of air inside the beverage can during crushing}

As mentioned earlier, the difference in the energy levels $\left(E_{\text {given }}-E_{a b s}\right)$ for the case with the initial impact velocity of $4.9 \mathrm{~m} / \mathrm{s}$ was higher compared to other cases (approximately 7.7\%). In order to investigate the difference the high speed images of this particular case were examined; as an example the high speed images from one of the tests are presented in Figure 14. After reaching a maximum deformation length during the first impact the elastic strain energy from the test specimen was given back to the impactor (spring back). In addition to the elastic strain energy given by the test specimen the air entrapped inside the test specimen played a major role. When the deformation length of the beverage can reached its maximum value the compressed air inside the beverage can provided an additional resistance to the impactor (refer Figure 14). Due to this combined effect, the impactor bounced back and dropped once more on the test specimen and the combined spring back energy (elastic strain energy + energy from compressed air) was absorbed by the beverage can in subsequent impacts. The developed internal pressure inside the beverage can caused an upward force, leading to a longer contact time between the impactor and the beverage can during rebound, and a higher rebound height. This phenomenon was noticed only for $50 \%$ of the tests. The occurrence of air entrapping and its resistance depend upon the perfect contact between the crushing platform and the test specimen. During the compression process the temperature of the compressed air should have increased; consequently, a part of the thermal energy from the compressed air was lost to the atmosphere (by convection through the beverage can wall and discharge of air from the top opening of the beverage can). For the remaining $50 \%$ of the tests the air escapes due to a minor gap between the test specimen and the crushing platform and hence the height of bounce back of the impactor was shorter. 


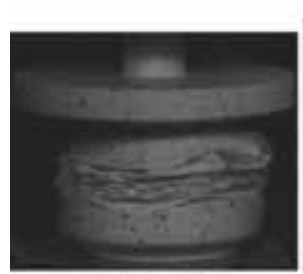

$t=30.4 \mathrm{~ms}$

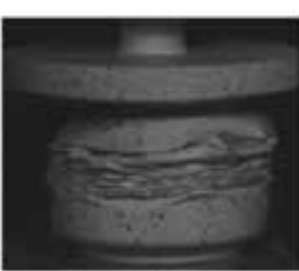

$\mathrm{t}=32.6 \mathrm{~ms}$

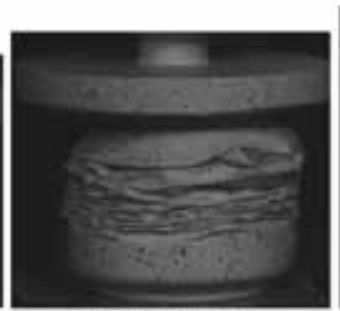

$\mathrm{t}=36.2 \mathrm{~ms}$

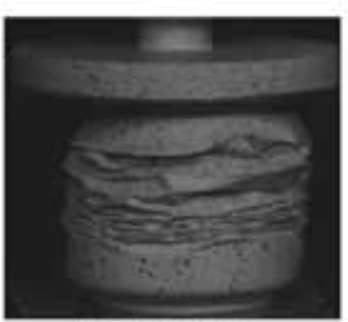

$\mathrm{t}=40.3 \mathrm{~ms}$

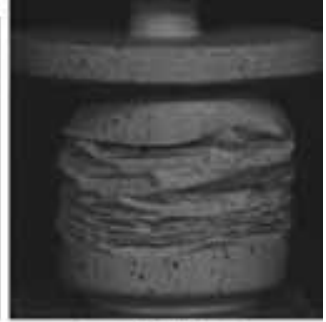

$\mathrm{t}=44.1 \mathrm{~ms}$ inside the test specimen for the initial impact velocity of $4.9 \mathrm{~m} / \mathrm{s}$.

In order to confirm the influence of air inside the beverage can additional tests have been conducted. To avoid the entrapping and consequent compression of the air during the crushing process, holes were drilled at the bottom of the beverage cans at four locations without deforming the beverage can (refer Figure 15). Experiments on these beverage cans (for the initial impact velocity of $4.9 \mathrm{~m} / \mathrm{s}$ ) showed a higher deformation length and corresponding energy, compared to the test specimen without holes. However, there was no difference in the deformation pattern compared to the ones without holes. Furthermore, there was a very minor spring back of the test specimen observed (refer Figure 16). The average crushing parameters (from 10 experiments) are reported in Table A1. It can be noticed that for the case with holes the difference in the energy levels $\left(E_{\text {given }}-E_{a b s}\right)$ was approximately reduced to $4.5 \%$. A comparison of the energy balance for the cases without and with holes is also shown in Figure 17(a) and 17(b) respectively. The total energy absorption of these cases was very close to the respective experimental average values. From these figures it can be noticed that the total energy given by the impactor (initial kinetic energy + additional potential energy due to the travelling mass of the impactor) for both cases was approximately the same (99.9 J). However, the total energy absorbed by the beverage can for the without holes case $(89.9 \mathrm{~J})$ was lower than for the case with holes $(96.1 \mathrm{~J})$. Due to this there was a significant difference in the energy loss observed for these two cases (refer Figure 17(a) and 17(b)). An additional evidence for the influence of the entrapped and compressed air can be observed from these figures. Due to the resistance provided by the compressed air, the total duration of the impact for the beverage can without holes was shorter $(26.9 \mathrm{~ms})$ than for the one with holes (31.4 ms). Therefore, it can be concluded from the results that the remaining $3 \%$ of energy loss was caused by the entrapped and compressed air inside the beverage can during the crushing process. In order to check the influence of air inside the beverage cans similar tests have been conducted for other impact velocity cases $(1.4 \mathrm{~m} / \mathrm{s}$ to $4.4 \mathrm{~m} / \mathrm{s})$. The results from these tests showed no significant difference in the crushing performance of these beverage cans (compared to the one without holes). 


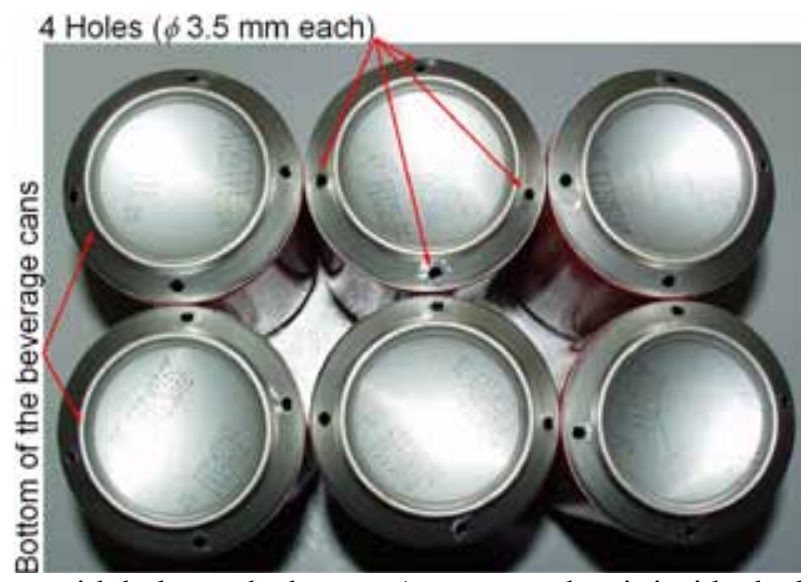

Figure 15: Beverage cans with holes at the bottom (to remove the air inside the beverage can during the crushing process).

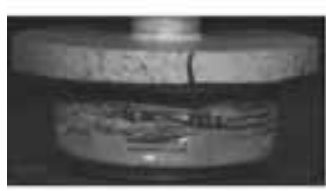

$\mathrm{t}=37.4 \mathrm{~ms}$

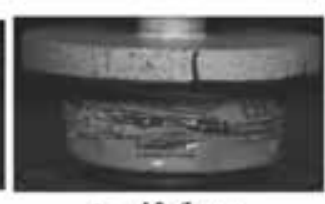

$\mathrm{t}=43.6 \mathrm{~ms}$

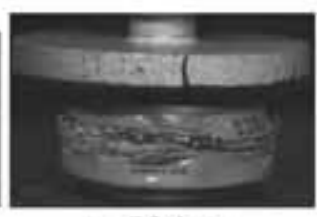

$\mathrm{t}=56.4 \mathrm{~ms}$

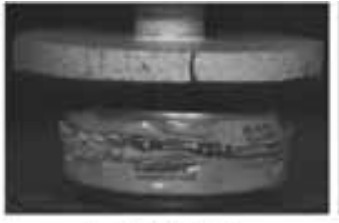

$\mathrm{t}=66.0 \mathrm{~ms}$

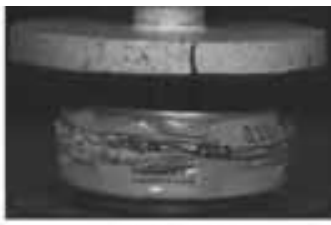

$\mathrm{t}=75.2 \mathrm{~ms}$

Figure 16: Separation and bounce of the impactor after crushing the beverage can with 4 holes ( $\phi 3.5 \mathrm{~mm}$ each) for the initial impact velocity of $4.9 \mathrm{~m} / \mathrm{s}$.

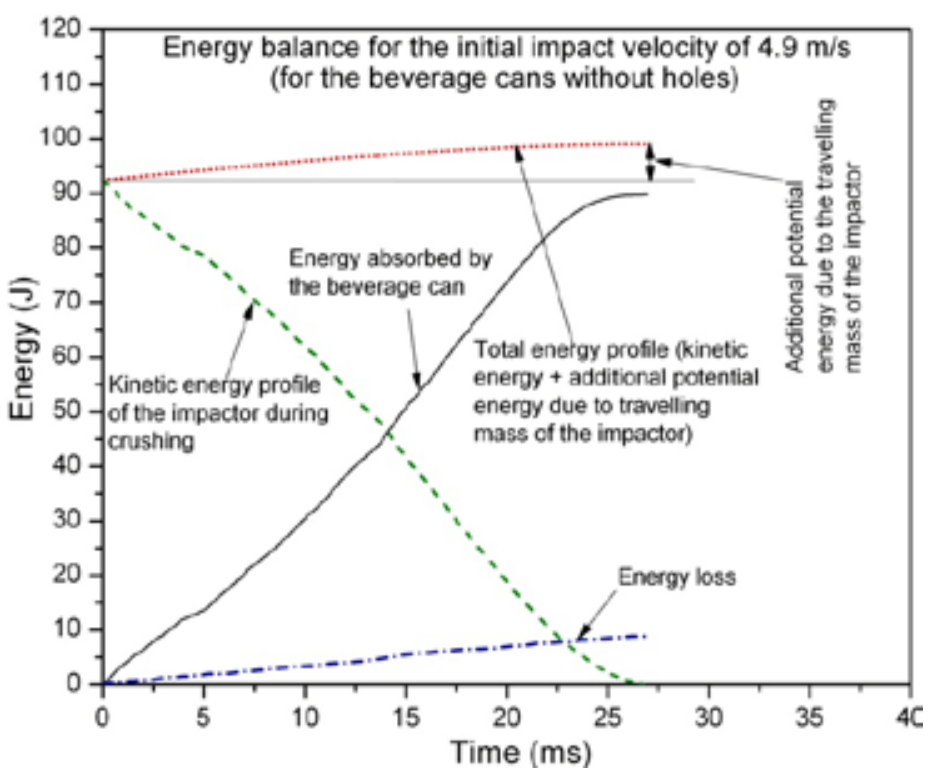

(a) Beverage can without holes

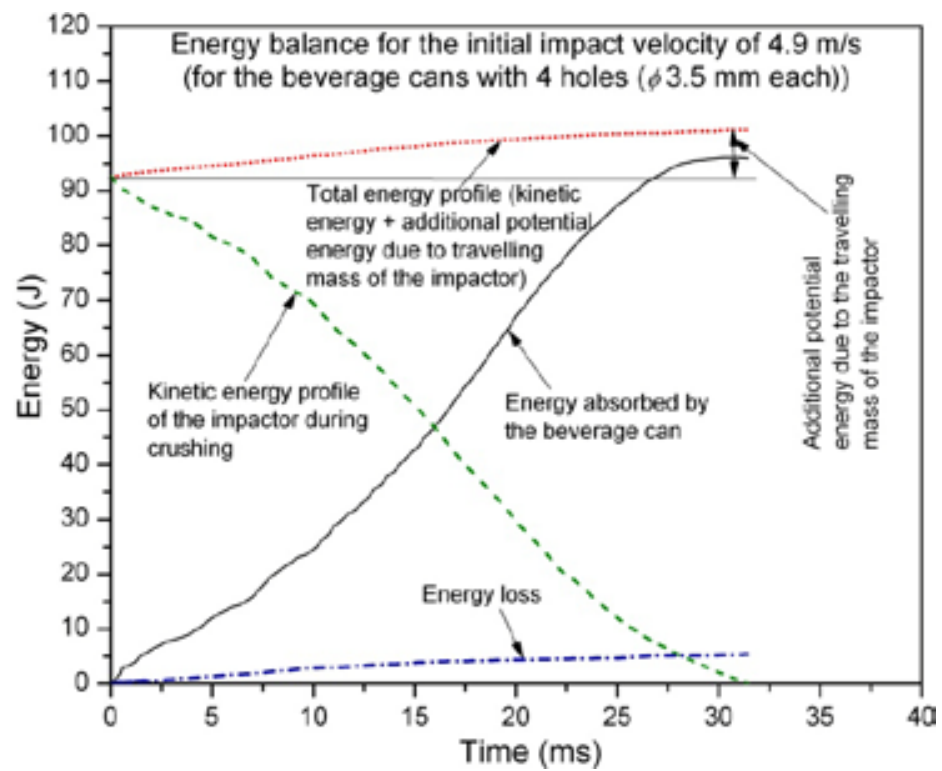

(b) Beverage can with holes at the bottom

Figure 17: Comparison of the experimental energy balance for the case with the initial impact velocity of 4.9 $\mathrm{m} / \mathrm{s}$ (for the test on beverage cans with and without holes).

\subsubsection{Effect of initial impact velocity on the performance parameters}

The effect of initial impact velocity on the performance parameters can be understood from Figure 18(a) and 18(b). It can also be noticed that the variation in SEA and peak crush load is quite low for these tests. The mean crush load of the beverage can was increased with increasing initial impact velocity. The mean crush load varied from a minimum of $413 \mathrm{~N}$ (for the case with $1.4 \mathrm{~m} / \mathrm{s}$ initial impact velocity) to a maximum of $1060 \mathrm{~N}$ (for the case with 4.9 $\mathrm{m} / \mathrm{s}$ initial impact velocity). The strain hardening of the material during onset collapse and 
folding process significantly contributed to increase the mean crush load. Consequently, the corresponding total energy absorption and the specific energy absorption of the beverage can was increased $(1.86 \mathrm{~kJ} / \mathrm{kg}, 2 \mathrm{~kJ} / \mathrm{kg}, 2.74 \mathrm{~kJ} / \mathrm{kg}, 3.48 \mathrm{~kJ} / \mathrm{kg}, 4.13 \mathrm{~kJ} / \mathrm{kg}$ and $4.72 \mathrm{~kJ} / \mathrm{kg}$ for 1.4 $\mathrm{m} / \mathrm{s}, 2.2 \mathrm{~m} / \mathrm{s}, 3.1 \mathrm{~m} / \mathrm{s}, 3.8 \mathrm{~m} / \mathrm{s}, 4.4 \mathrm{~m} / \mathrm{s}$ and $4.9 \mathrm{~m} / \mathrm{s}$ initial impact velocities respectively). Furthermore, the initial peak crush load was increased with increasing initial impact velocity (1.69 kN, $1.72 \mathrm{kN}, 2.19 \mathrm{kN}, 2.28 \mathrm{kN}, 2.37 \mathrm{kN}$ and $2.46 \mathrm{kN}$ for $1.4 \mathrm{~m} / \mathrm{s}, 2.2 \mathrm{~m} / \mathrm{s}, 3.1 \mathrm{~m} / \mathrm{s}, 3.8$ $\mathrm{m} / \mathrm{s}, 4.4 \mathrm{~m} / \mathrm{s}$ and $4.9 \mathrm{~m} / \mathrm{s}$ initial impact velocities respectively). This clearly indicates the strain rate dependency on the material behaviour.

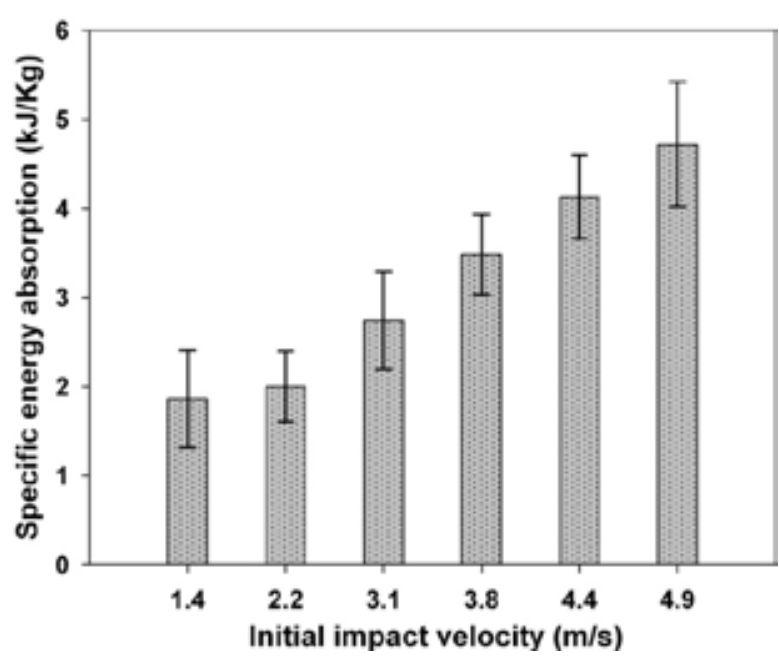

(a) Specific energy absorption

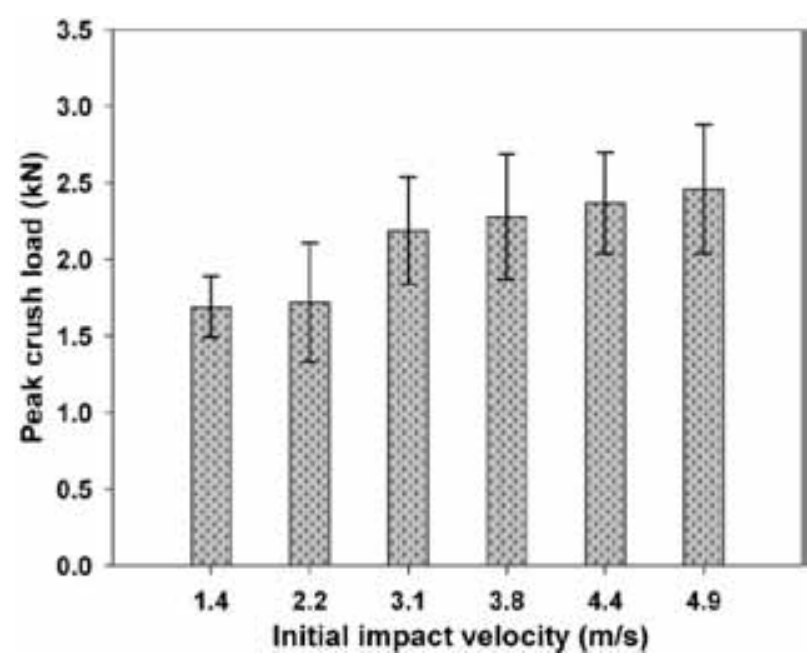

(b) Peak crush load

Figure 18: Effect of initial impact velocity on the specific energy absorption and peak crush load of an empty beverage can (error bar indicates the standard deviation).

\section{Analytical model}

In this section an analytical model is established to calculate the deformation length and the corresponding energy absorption of the empty beverage can subjected to the axial impact loading condition. The total kinetic energy of the impactor before impact (equal to the potential energy for certain drop height having an initial impact velocity) and the additional potential energy due the travelling mass of the impactor during the crushing process has been used to deform the empty beverage can. Hence, we write the force equilibrium for this system as (Equation 9),

$$
F_{c}(t)=M_{I} \cdot\left(\frac{d v}{d t}+g\right)=\frac{d}{d x}\left(E_{a b s}\right)
$$

where $\frac{d v}{d t}=a(t)$ is the acceleration of the impactor $\left(\mathrm{m} / \mathrm{s}^{2}\right) ; \frac{d}{d x}\left(E_{a b s}\right)$ is the energy absorbed per crushed empty beverage can length $(\mathrm{J} / \mathrm{m}) ; E_{a b s}(x)$ is the energy absorbed by the beverage can $(\mathrm{J})$ as a function of crushing length using a qualitative term called 'dynamic mean crush load” (Equation 10).

$$
E_{a b s}(x)=P_{\text {mean }} \cdot x
$$

where $x$ is the deformation length of the beverage can. The expression to calculate the dynamic mean crush load of the empty beverage can considering diamond mode is discussed later. Equation 9 can be integrated by means of the "Runge-Kutta" integration scheme where 
the second order differential equation can be split in two single order equations using "Odesolve" function of MathCAD [38]. The initial condition for velocity and displacement of the impactor are as follows:

$$
v(0)=v_{0}=\sqrt{2 g h} ; \quad x(0)=0
$$

where $h$ is the drop height of the impactor (m).

\subsection{Expression for dynamic mean crush load}

As we noticed from Figure 8(a-f) there was no significant deformation noticed for top and bottom shoulders and end caps. Hence, for simplification the beverage can can be considered as a cylindrical structure and subsequently the stability provided by the top and bottom end caps can also be neglected. The diamond mode crushing characteristics of thinwalled structures by the formation of triangular lobes considering total bending and the corresponding membrane energies (contributing in converting the tube into collated and flattened triangles) are well studied in ref. [16]. Furthermore, the development of initial and successive lobes and their corresponding angle relationship for inward and outwards fold are given. The triangular formation at the start of this impact event (for an initial impact velocity of $2.2 \mathrm{~m} / \mathrm{s}$ ) and during crushing (for an initial impact velocity of $4.4 \mathrm{~m} / \mathrm{s}$ ) and the corresponding geometrical relationships are given in Figure 19(a) and 19(b).

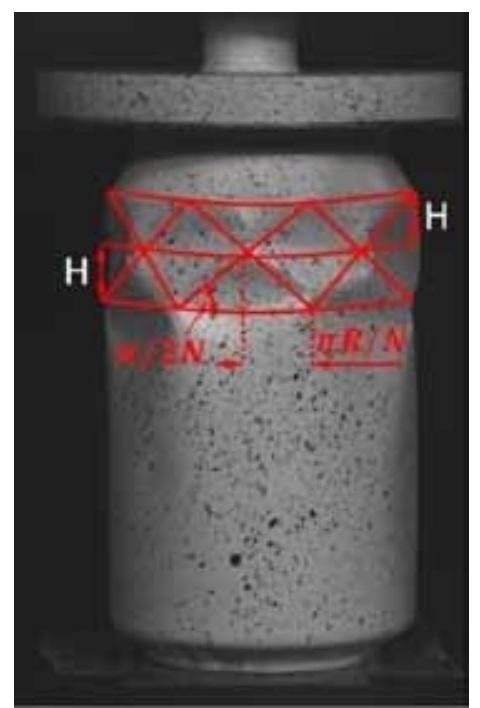

(a)

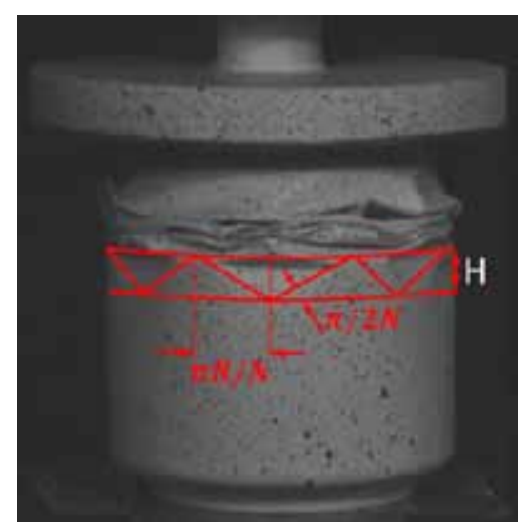

(b)

Figure 19: (a) Formation of triangular lobes at the start of the impact process for an initial impact velocity of $2.2 \mathrm{~m} / \mathrm{s}$. (b) Formation of triangular lobes during the crushing process for an initial impact velocity of $4.4 \mathrm{~m} / \mathrm{s}$.

Singace [16] has proposed an expression to calculate the mean crush load of a tubular structure (which exhibits asymmetric or diamond deformation pattern) under quasi-static compressive loading condition. The following modes of deformation were accounted for to calculate the mean crush load: (i) bending energy - which comprises the de-curving of the tube wall into triangles and the rotation of the triangles about their base and side edges (ii) membrane energy at the base of the triangle (i.e) the energy required to compress an element of the tube wall towards the axis of the tube. (iii) membrane energy at the apex of the triangle, i.e the energy required to push an element of the tube wall outwards (away from the 
axis of the tube). The mean crush load of a tubular structure that exhibits asymmetric or diamond mode is given by [16],

$$
\frac{P_{\text {mean }}}{M_{p}} \cong \frac{4 \pi H}{t}-\frac{\pi \mathrm{N}}{3}
$$

where $H$ is the half fold length (m); $N$ is the number of lobes; $t$ is the thickness of the tubular structure (m); $M_{p}$ is full plastic bending moment per unit length which can be written as follows [16],

$$
M_{p} \cong \frac{\sigma_{y} t^{2}}{2 \sqrt{3}}
$$

where $\sigma_{y}$ is the yield stress of the tubular structure (MPa). The above model (Equation 12) can be extended to the impact loadings with the method used by Abramowicz and Jones [24]. Among rate-dependent constitutive equations, the Cowper-Symonds equation has been most popularly employed in structural impact problems. This relation represents a rigid, perfectly plastic material with dynamic yield or flow stress that depends on strain rate. The ratio of dynamic yield stress $\sigma_{y}^{d}$ and static yield stress $\sigma_{y}$ is [24],

$$
\frac{\sigma_{y}^{d}}{\sigma_{y}}=1+\left(\frac{\dot{\varepsilon}}{C}\right)^{1 / p}
$$

where $C$ (characteristic strain rate) and $p$ (measure of the strain rate sensitivity) are material constants; $\dot{\mathcal{E}}$ is the strain rate. Using Equation 13 and 14, the Equation 12 can be written as follows (Equation 15),

$$
P_{\text {mean }} \cong \frac{\sigma_{y} t^{2}}{2 \sqrt{3}}\left(\frac{4 \pi H}{t}-\frac{\pi \mathrm{N}}{3}\right) \cdot\left[1+\left(\frac{\dot{\varepsilon}}{C}\right)^{1 / p}\right]
$$

To estimate the strain rate over collapse process, a simple estimate for the mean circumferential strain $(\varepsilon)$ for a completely flattened fold of the circular tube is [16],

$$
\mathcal{E} \cong \frac{H}{D}
$$

where $D$ is the average diameter of the beverage can at mid-wall region (65.63 mm). It was assumed that the empty beverage can deforms with an initial impact velocity of $v_{0}$ and this velocity decreases linearly with time (this assumption is experimentally supported by the integrated velocity-time profile of the impactor from the acceleration signal - refer Figure 5(b)). This corresponds to a constant deceleration of the impactor during the crushing process. For the simplification, the effect of additional potential energy during the crushing process on the strain rate was neglected. Furthermore, the air resistance inside the can for the 
$50 \%$ of the cases with the initial impact velocity of $4.9 \mathrm{~m} / \mathrm{s}$ was not accounted. The time taken to deform for one complete fold $(T)$ and the corresponding average strain rate $(\dot{\varepsilon})$ can be given as Equation 17 and 18 respectively.

$$
\begin{gathered}
T=\frac{2 H}{v_{0}} \\
\dot{\mathcal{E}} \cong \frac{\mathcal{\varepsilon}}{T}=\frac{v_{0}}{2 D}
\end{gathered}
$$

Now, substituting Equation 17 into Equation 15 gives the mean crush load of that structure including the strain rate effect for a particular initial impact velocity (Equation 19),

$$
P_{\text {mean }} \cong \frac{\sigma_{y} t^{2}}{2 \sqrt{3}}\left(\frac{4 \pi H}{t}-\frac{\pi \mathrm{N}}{3}\right) \cdot\left[1+\left(\frac{v_{0}}{2 D C}\right)^{1 / p}\right]
$$

Experimental studies have proved that structures with high $D / t$ ratio and/or material sensitive to strain hardening would generally deform in diamond mode [16-19]. Further, as we noticed from the experimental results the mean crush load of the beverage can significantly increase after $30 \mathrm{~mm}$ of deformation length for $3.8 \mathrm{~m} / \mathrm{s}, 4.4 \mathrm{~m} / \mathrm{s}$ and $4.9 \mathrm{~m} / \mathrm{s}$. This was due to strain hardening of the material during the onset collapse, flattening and subsequent compression of each lobe. Therefore, to capture the appropriate mean crush load of beverage cans for these impact velocities the effect of strain hardening has to be included in the above expression. The effect of strain hardening of any material can be captured with yield stress and plastic strain using Ludwik equation [35]. Assuming the mean circumferential strain as the plastic strain the final form of the dynamic mean crush load of a thin tubular structure subjected to impact loading can be written as follows (Equation 20),

$$
P_{\text {mean }} \cong \frac{\sigma_{y}+B(H / D)^{n} t^{2}}{2 \sqrt{3}}\left(\frac{4 \pi H}{t}-\frac{\pi N}{3}\right) \cdot\left[1+\left(\frac{v_{0}}{2 D C}\right)^{1 / p}\right]
$$

where $B$ and $n$ are material constants (usually calculated from experimental data). The final material parameters of the manufactured steel beverage cans are very close to the steel grade 4340 [35]. The corresponding values for steel 4340 are given in Table 1 [33, 37]. Substituting the value obtained from Equation 20 for a particular initial impact velocity in Equation 10 and subsequently, solving of Equation 9 provides the total deformation length and the corresponding energy absorption of the tubular structure (beverage can). The choice of mean crush load equation 19 or 20 should be based on the initial impact velocity and the corresponding strain rate and strain hardening properties of the material. For lower impact velocities the consideration of Equation 19 can provide reasonable results; however for the impact velocities where the chances of strain hardening of the material are more, consideration of Equation 20 can yield close results compared to the experimental values. 


\subsection{Comparison of analytical and experimental results}

\subsubsection{Comparison of dynamic mean crush load}

Due to the inconsistent failure pattern, the case with an initial impact velocity of 1.4 $\mathrm{m} / \mathrm{s}$ was not considered for the calculation of dynamic mean crush load. A comparison of dynamic mean crush loads for the remaining cases is given in Figure 20. The dynamic mean crush load using Equation 19 yielded a good correlation for the case with an initial impact velocity of $2.2 \mathrm{~m} / \mathrm{s}$. For the remaining cases (from $3.1 \mathrm{~m} / \mathrm{s}$ to $4.9 \mathrm{~m} / \mathrm{s}$ ), there was a significant difference noted from the experimental data. Equation 19 predicted lower values compared to the experimental data. The major reason for this difference is the absence of the strain hardening effect which was observed in all cases. On the other hand, Equation 20 provided reasonable results for all impact velocities. The difference between the experimental and analytical solution was gradually reduced for higher impact velocities. Hence, it can be concluded that the consideration of strain rate and the corresponding hardening characteristics of the beverage can material is absolutely necessary to calculate the dynamic mean crush load.

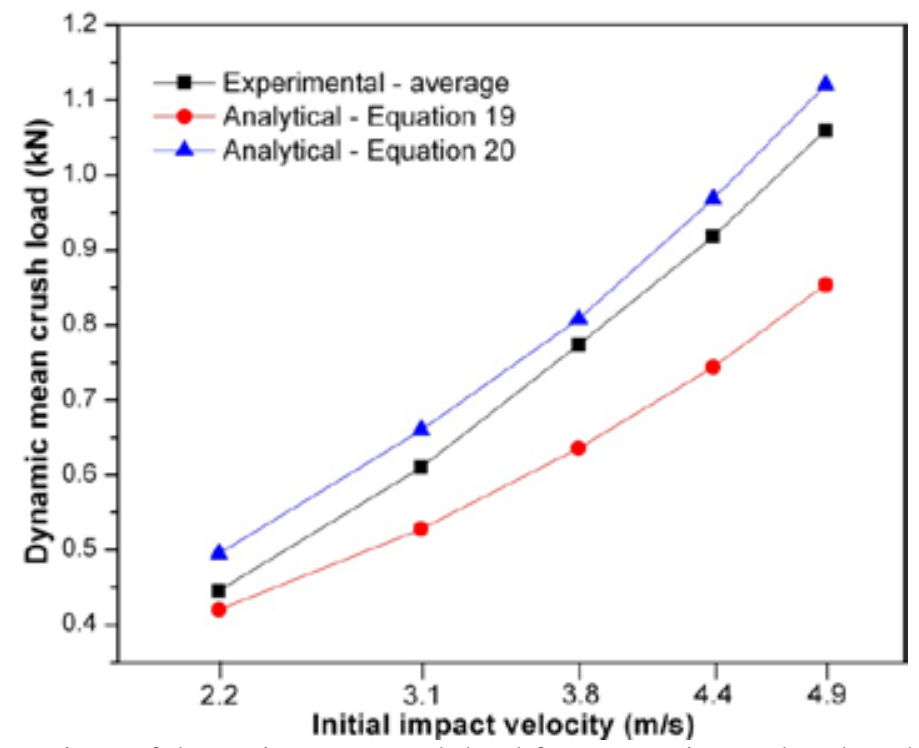

Figure 20: Comparison of dynamic mean crush load from experimental and analytical solutions.

\subsubsection{Comparison of crushing parameters}

The crushing performance of an empty beverage can can be calculated considering the values from Figure 20. Substituting these values of dynamic mean crush load in Equation 10 and solving Equation 9, the corresponding crushing performance (deformation, velocity and energy histories with respect to time) of the beverage can was calculated. The calculated performance values for all cases are given in Table 2. As an example, the initial impact velocity of $3.8 \mathrm{~m} / \mathrm{s}$ case is discussed here. Figure 21(a), 21(b) and 21(c) show a comparison of deformation, velocity and the corresponding energy absorption of experimental and analytical solutions respectively. The dotted line is an experimental curve (one of the tests with the deformation length close to the average deformation length from 10 tests); the second curve (dashed line) represents the analytical solution considering the average dynamic mean crush load from the experiments; and the third solid curve shows the analytical solution considering Equation 20. The results from these three cases showed a good correlation of parameters such as deformation length, velocity and the corresponding energy absorption. 
Compared to experimental data there was a difference in the total impact duration noticed (Figure 21(a-c)). This was due to the change in crush load and the corresponding deceleration of impactor during the experimental crushing process. However, the analytical formulation uses a constant mean crush load (the decrease in velocity and the corresponding deceleration were linear).
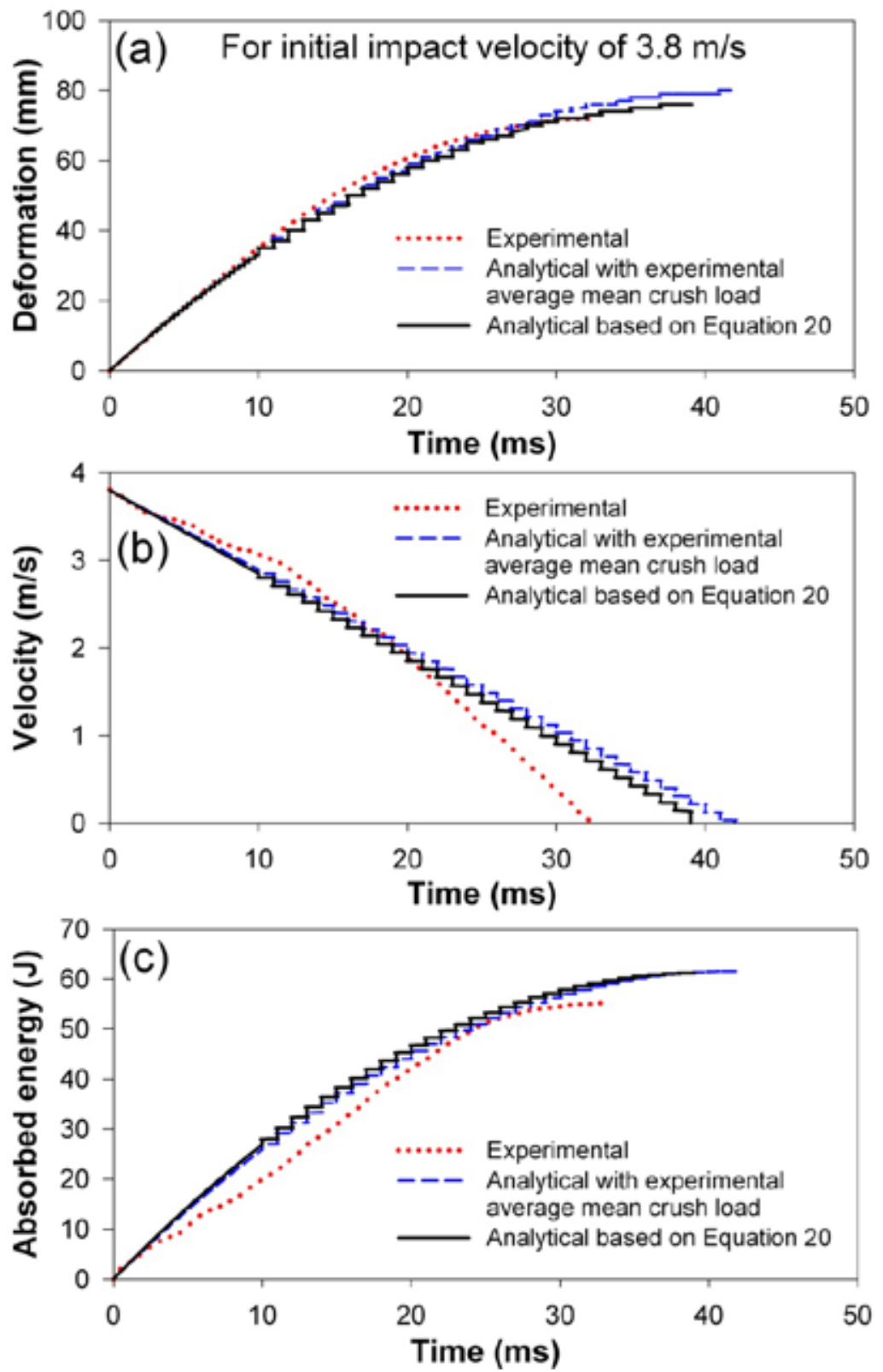

Figure 21: Comparison of crushing parameters of experimental and analytical solutions. (a) deformation time history (b) velocity time history (c) energy absorption history.

Similarly, Figure 22 shows the energy balance during the crushing process. It can be noticed that the total energy given by the impactor is increased due to the travelling mass of the impactor during the crushing process. The initial kinetic energy and the total energy given by the impactor were $55.6 \mathrm{~J}$ and $61.2 \mathrm{~J}$ respectively. An incremental energy value of $4.6 \mathrm{~J}$ was obtained from the additional potential energy from the travelling mass of the impactor during the crushing process. 


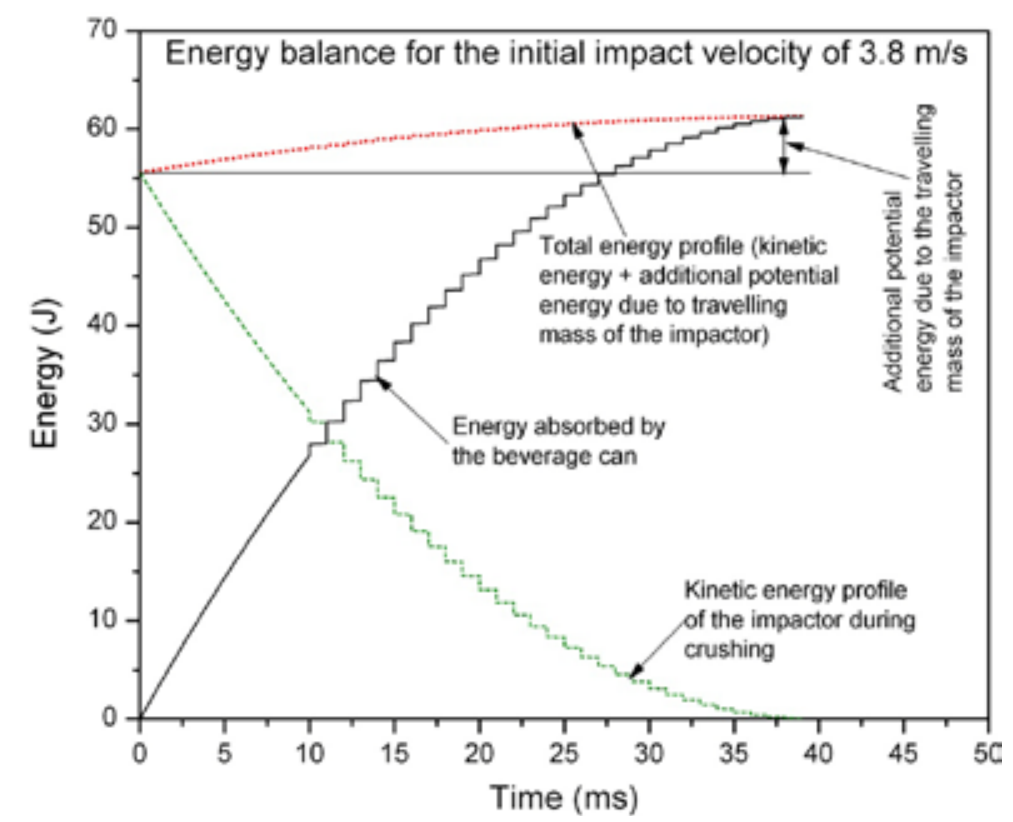

Figure 22: Energy balance for the case with the initial impact velocity of $3.8 \mathrm{~m} / \mathrm{s}$.

\section{Conclusions}

In this study the axial impact energy absorption characteristics and the corresponding deformation mechanism of empty recyclable metal beverage cans were investigated. Axial impact tests have been conducted for different initial impact velocities ranging from $1.4 \mathrm{~m} / \mathrm{s}$ to $4.9 \mathrm{~m} / \mathrm{s}$. An analytical model is also developed to predict the performance parameters of the beverage cans. From the conducted experiments the following conclusions can be made:

- $\quad$ For all initial impact velocities $(2.2 \mathrm{~m} / \mathrm{s}, 3.1 \mathrm{~m} / \mathrm{s}, 3.8 \mathrm{~m} / \mathrm{s}, 4.4 \mathrm{~m} / \mathrm{s}$ and $4.9 \mathrm{~m} / \mathrm{s})$ the empty beverage cans showed controlled and uniform crushing failure modes. Furthermore, these beverage cans exhibited a diamond mode deformation pattern (formation of fold legs around the circumference and collapse and fold of triangular folds) (except for the case with an initial impact velocity of $1.4 \mathrm{~m} / \mathrm{s}$ ).

- $\quad$ The peak crush load of beverage cans with different initial impact velocities showed the strain rate sensitivity consistently. Hence, the effect of strain rate on increasing yield strength should be taken into account for dynamic investigations.

- $\quad$ The mean crush load and the corresponding specific energy absorption of these cans increased with increasing initial impact velocities. Furthermore, this test has given a guideline that these cans should be deployed for the maximum allowable deformation length of $80 \mathrm{~mm}$.

- $\quad$ For the tests with the initial impact velocity of $4.9 \mathrm{~m} / \mathrm{s}$ the air trapped inside the beverage can consumed 3\% of the total energy given during the impact process.

- An analytical solution including the strain rate and strain hardening effects of the material provided the mean crush loads which are very close to the experimental results. Furthermore, the other parameters such as deformation length, velocity and the corresponding energy absorption are very close to the experimental data.

\section{Acknowledgements}


The authors gratefully acknowledge the financial support of the "Fund for Scientific Research" - Flanders (F.W.O) (Grant No: G.0114.07). The authors appreciate the technical input of Mr. Paul Tamis and his colleagues from TATA Steel (earlier Corus), Research Development \& Technology, Ijmuiden, The Netherlands.

\section{References}

[1] S. Guruprasad and Abhijit Mukherjee, Layered sacrificial claddings under blast loading Part I -- analytical studies. International Journal of Impact Engineering, 2000. 24(9): p. 957-973.

[2] S. Guruprasad and Abhijit Mukherjee, Layered sacrificial claddings under blast loading Part II -- experimental studies. International Journal of Impact Engineering, 2000. 24(9): p. 975-984.

[3] A. G. Hanssen, L. Enstock and M. Langseth, Close-range blast loading of aluminium foam panels. International Journal of Impact Engineering, 2002. 27(6): p. 593-618.

[4] Z. Zou, P. J. Tan, S. R. Reid, S. Li and J. J. Harrigan, Dynamic crushing of a onedimensional chain of type II structures. International Journal of Impact Engineering, 2007. 34(2): p. 303-328.

[5] S. R. Yella Reddy T. Reid, Experimental investigation of inertia effects in onedimensional metal ring systems subjected to end impact -I. Fixed end systems. International Journal of Impact Engineering, 1983. 1(1): p. 85-106.

[6] M Alves R.E.Oshiro, Scaling impact structures. Archive of applied mechanics, 2004. 74: p. 130-145.

[7] X. Y. Su, T. X. Yu and S. R. Reid, Inertia-sensitive impact energy-absorbing structures part I: Effects of inertia and elasticity. International Journal of Impact Engineering, 1995. 16(4): p. 651-672.

[8] X. Y. Su, T. X. Yu and S. R. Reid, Inertia-sensitive impact energy-absorbing structures part II: Effect of strain rate. International Journal of Impact Engineering, 1995. 16(4): p. 673-689.

[9] C. R. Calladine and R. W. English, Strain-rate and inertia effects in the collapse of two types of energy-absorbing structure. International Journal of Mechanical Sciences, 1984. 26(11-12): p. 689-701.

[10] Z. Y. Gao, T. X. Yu and G. Lu, A study on type II structures. Part I:: a modified onedimensional mass-spring model. International Journal of Impact Engineering, 2005. 31(7): p. 895-910.

[11] L. L. Tam and C. R. Calladine, Inertia and strain-rate effects in a simple platestructure under impact loading. International Journal of Impact Engineering, 1991. 11(3): p. 349-377.

[12] D. Karagiozova and Marcílio Alves, Transition from progressive buckling to global bending of circular shells under axial impact--Part I: Experimental and numerical observations. International Journal of Solids and Structures, 2004. 41(5-6): p. 15651580.

[13] D. Karagiozova and Marcílio Alves, Transition from progressive buckling to global bending of circular shells under axial impact--Part II: Theoretical analysis. International Journal of Solids and Structures, 2004. 41(5-6): p. 1581-1604.

[14] W. Abramowicz and N. Jones, Transition from initial global bending to progressive buckling of tubes loaded statically and dynamically. International Journal of Impact Engineering, 1997. 19(5-6): p. 415-437. 
[15] Norman Jones and Joao G. De Oliveira, Impulsive loading of a cylindrical shell with transverse shear and rotatory inertia. International Journal of Solids and Structures, 1983. 19(3): p. 263-279.

[16] A. A. Singace, Axial crushing analysis of tubes deforming in the multi-lobe mode. International Journal of Mechanical Sciences, 1999. 41(7): p. 865-890.

[17] W. Horton, S. Bailey and A. Edwards, Nonsymmetric buckle patterns in progressive plastic buckling. Experimental Mechanics, 1966. 6(9): p. 433-444.

[18] Alfred Pugsley, On the crumpling of thin tubular struts. Quartely Journal of Mechanics Applied Mathematics, 1979. 32(1): p. 1-7.

[19] W. Johnson, P. Soden and S. Al-Hassani, Inextensional collapse of thin-walled tubes under axial compression. The Journal of Strain Analysis for Engineering Design, 1977. 12(4): p. 317-330.

[20] K. R. F. Andrews, G. L. England and E. Ghani, Classification of the axial collapse of cylindrical tubes under quasi-static loading. International Journal of Mechanical Sciences, 1983. 25(9-10): p. 687-696.

[21] A. A. Singace, H. El-Sobky and M. Petsios, Influence of end constraints on the collapse of axially impacted frusta. Thin-Walled Structures, 2001. 39(5): p. 415-428.

[22] S.S.Hsu and N.Jones, Dynamic axial crushing of aluminium alloy 6063 -T6 circular tubes. Latin American Journal of Solids and Structures, 2004(1): p. 277-296.

[23] T. Y. Reddy and E. Zhang, Effect of strain-hardening on the behaviour of axially crushed cylindrical tubes. In:Lee WB, Editor. Advances in engineering plasticity and its applications. London:Elsevier, 1993: p. 755-762.

[24] W. Abramowicz and N. Jones, Dynamic axial crushing of circular tubes. International Journal of Impact Engineering, 1984. 2(3): p. 263-281.

[25] J.M. Alexander, An approximate analysis of the collapse of thin cylindrical shells under axial load. Quart. J. Mech. App. Math., 1960. 13: p. 10-15.

[26] N.Jones D.Karagiozova, Inertia effects in square tubes sujected to an axial impact, in: N.Jones, C.A .Brebbia and A.M. Rajendran (Eds.), WIT Transactions on Engineering Sciences, 2005. 49(Structures under Shock and Impact VII): p. 531-540.

[27] T. Wierzbicki, S. U. Bhat, W. Abramowicz and D. Brodkin, Alexander revisited--A two folding elements model of progressive crushing of tubes. International Journal of Solids and Structures, 1992. 29(24): p. 3269-3288.

[28] A. A. Singace, H. Elsobky and T. Y. Reddy, On the eccentricity factor in the progressive crushing of tubes. International Journal of Solids and Structures, 1995. 32(24): p. 3589-3602.

[29] A. A. Singace and H. Elsobky, Further experimental investigation on the eccentricity factor in the progressive crushing of tubes. International Journal of Solids and Structures, 1996. 33(24): p. 3517-3538.

[30] W. Abramowicz and N. Jones, Dynamic progressive buckling of circular and square tubes. International Journal of Impact Engineering, 1986. 4(4): p. 243-270.

[31] J. Amdahl and T.H. Soreide, Energy absorption in axially compressed cylindrical shells with special reference to bulbous bows in collision. Norwegian Maritime Research, 1981(4): p. 2-11.

[32] Alfred Pugsley and M Macaulay, The large-scale crumpling of thin cylindrical columns. Quarterly Journal of Mechanics Applied Mathematics, 1960. 13(1): p. 1-9.

[33] William H.Cook. Gordon R.Johnson, Fracture characteristics of three metals subjected to various strains, strain rates, temperatures and pressures. Engineering fracture mechanics, 1985. 21(1): p. 31-48. 
[34] Donald Lesuer, Experimental Investigations of Material Models for Ti-6Al-4V Titanium and 2024-T3 Aluminum.U.S. Department of Transportation.DOT/FAA/AR00/25,Sept. 2000

[35] Private communication from TATA Steel s(earlier Corus), in The Netherlands to the Department of Materials Science and Engineering, Ghent University, Belgium. 2010.

[36] Eric Markiewicz, Pierre Ducrocq and Pascal Drazetic, An inverse approach to determine the constitutive model parameters from axial crushing of thin-walled square tubes. International Journal of Impact Engineering, 1998. 21(6): p. 433-449.

[37] Miguel Angel Calle Gonzales., Daniel Ben'Itez Barrios., Nelson Batista De Lima. and Edison Goncalves., Importance of considering a material micro-failure criterion in the numerical modelling of the shot peening process applied to parabolic leaf springs in Latin American journal of Solids and Structures. 2010. 7: p. 21-40.

[38] User Manual Mathcad, Mathsoft Engineering \& Education, 2005. 